\title{
CORONAVIRUS
}

\section{An orally bioavailable broad-spectrum antiviral inhibits SARS-CoV-2 in human airway epithelial cell cultures and multiple coronaviruses in mice}

\author{
Timothy P. Sheahan ${ }^{1 *}+$, Amy C. Sims ${ }^{1 *}$, Shuntai Zhou ${ }^{2}$, Rachel L. Graham1, Andrea J. Pruijssers ${ }^{3}$, Maria L. \\ Agostini $^{3}$, Sarah R. Leist ${ }^{1}$, Alexandra Schäfer ${ }^{1}$, Kenneth H. Dinnon III ${ }^{1,4}$, Laura J. Stevens ${ }^{3}$, James D. Chappell ${ }^{3}$, \\ Xiaotao Lu ${ }^{3}$, Tia M. Hughes ${ }^{3}$, Amelia S. George ${ }^{3}$, Collin S. Hill ${ }^{2}$, Stephanie A. Montgomery ${ }^{5}$, Ariane J. Brown', \\ Gregory R. Bluemling ${ }^{6,7}$, Michael G. Natchus ${ }^{6}$, Manohar Saindane ${ }^{6}$, Alexander A. Kolykhalov ${ }^{6,7}$, George \\ Painter $^{6,7,8}$, Jennifer Harcourt ${ }^{9}$, Azaibi Tamin ${ }^{9}$, Natalie J. Thornburg ${ }^{9}$, Ronald Swanstrom ${ }^{2,10}$, Mark R. Denison $^{3}$, \\ Ralph S. Baric ${ }^{1,4}+$
}

\begin{abstract}
${ }^{1}$ Department of Epidemiology, University of North Carolina at Chapel Hill, Chapel Hill, NC, 27599, USA. 'Lineberger Comprehensive Cancer Center, University of North Carolina at Chapel Hill, Chapel Hill, NC, 27599, USA. ${ }^{3}$ Department of Pediatrics, Vanderbilt University Medical Center, Nashville, TN, TN, 37232,USA ${ }^{4}$ Department of Microbiology and Immunology, University of North Carolina at Chapel Hill, Chapel Hill, NC ${ }^{5}$ Department of Pathology \& Laboratory Medicine, University of North Carolina, Chapel Hill, NC, 27599, USA. ${ }^{6}$ Emory Institute of Drug Development (EIDD), Emory University, Atlanta, GA, 30322, USA. 'Drug Innovation Ventures at Emory (DRIVE), Atlanta, GA, 30322, USA. ${ }^{8}$ Department of Pharmacology and Chemical Biology, Emory University, Atlanta, GA, 30322, USA. ${ }^{\circ}$ Centers for Disease Control and Prevention, Division of Viral Diseases Atlanta GA ${ }^{10}$ Department of Biochemistry and Biophysics, University of North Carolina at Chapel Hill, Chapel Hill, NC
\end{abstract}

*Authors contributed equally.

\$ Current address for A.C.S. is Chemical and Biological Signature Sciences, National Security Division, Pacific Northwest National Laboratory, Richland, WA 99352, USA. †Corresponding author. Email: Timothy P. Sheahan sheahan@email.unc.edu and Ralph S. Baric rbaric@email.unc.edu

Coronaviruses (CoVs) traffic frequently between species resulting in novel disease outbreaks, most recently exemplified by the newly emerged SARS-CoV-2, the causative agent of COVID-19. Herein, we show that the ribonucleoside analog $\beta$-D-N4-hydroxycytidine (NHC, EIDD-1931) has broad spectrum antiviral activity against SARS-CoV-2, MERS-CoV, SARS-CoV, and related zoonotic group $2 \mathrm{~b}$ or $2 \mathrm{c}$ Bat-CoVs, as well as increased potency against a coronavirus bearing resistance mutations to the nucleoside analog inhibitor remdesivir. In mice infected with SARS-CoV or MERS-CoV, both prophylactic and therapeutic administration of EIDD-2801, an orally bioavailable NHC-prodrug ( $\beta$-D-N ${ }^{4}$-hydroxycytidine-5'-isopropyl ester), improved pulmonary function, and reduced virus titer and body weight loss. Decreased MERS-CoV yields in vitro and in vivo were associated with increased transition mutation frequency in viral but not host cell RNA, supporting a mechanism of lethal mutagenesis in CoV. The potency of NHC/EIDD-2801 against multiple coronaviruses and oral bioavailability highlight its potential utility as an effective antiviral against SARS-CoV-2 and other future zoonotic coronaviruses.

\section{INTRODUCTION}

The genetically diverse Orthocoronavirinae (coronavirus, $\mathrm{CoV}$ ) family circulates in many avian and mammalian species. Phylogenetically, CoVs are divided into 4 genera: alpha (group 1), beta (group 2), gamma (group 3) and delta (group 4). Three new human CoV have emerged in the past 20 years with severe acute respiratory syndrome CoV (SARS-CoV) in 2002, Middle East respiratory syndrome CoV (MERS-CoV) in 2012, and now SARS-CoV-2 in 2019 (1-3). In fact, all human $\mathrm{CoV}$ are thought to have emerged originally as zoonoses (46 ). The ongoing SARS-CoV-2 pandemic (referred to as COVID-19, Coronavirus disease 2019) has caused over 500,000 infections and over 25,000 deaths in 199 countries.
Like SARS- and MERS-CoV, the respiratory disease caused by SARS-CoV-2 can progress to acute lung injury (ALI), an end stage lung disease with limited treatment options and very poor prognoses $(3,7,8)$. This emergence paradigm is not limited to humans. A novel group $1 \mathrm{CoV}$ called swine acute diarrhea syndrome CoV (SADS-CoV) recently emerged from bats causing the loss of over 20,000 pigs in Guangdong Province, China (9). More alarmingly, many group 2 SARS-like and MERS-like coronaviruses are circulating in bat reservoir species that can use human receptors and replicate efficiently in primary human lung cells without adaptation(9-12). The presence of these "pre-epidemic" zoonotic strains foreshadow the emergence and epidemic potential of additional SARS- 
like and MERS-like viruses in the future. Given the diversity of $\mathrm{CoV}$ strains in zoonotic reservoirs and a penchant for emergence, broadly active antivirals are clearly needed for rapid response to new $\mathrm{CoV}$ outbreaks in humans and domesticated animals.

Currently, there are no approved therapies specific for any human CoV. $\beta$-D-N4-hydroxycytidine (NHC, EIDD-1931) is orally bioavailable ribonucleoside analog with broad-spectrum antiviral activity against various unrelated RNA viruses including influenza, Ebola, CoV, and Venezuelan equine encephalitis virus (VEEV)(13-16). For VEEV, the mechanism of action (MOA) for NHC has been shown to be through lethal mutagenesis where deleterious transition mutations accumulate in viral $\mathrm{RNA}(14,17)$. Thus, we sought to determine NHC's breadth of antiviral activity against multiple emerging $\mathrm{CoV}$, its mechanism of action for $\mathrm{CoV}$ and its efficacy in mouse models of $\mathrm{CoV}$ pathogenesis.

\section{RESULTS}

\section{NHC potently inhibits MERS-CoV and newly emerging SARS-CoV-2 replication}

To determine whether NHC blocks the replication of highly pathogenic human $\mathrm{CoV}$, we performed antiviral assays in cell lines with MERS-CoV and the newly emerging SARS-CoV-2. We first assessed the antiviral activity of NHC against MERS$\mathrm{CoV}$ in the human lung epithelial cell line Calu-3 2B4 ("Calu3" cells). Using a recombinant MERS-CoV expressing nanoluciferase (MERS-nLUC)(18), we measured virus replication in cultures exposed to a dose range of drug for $48 \mathrm{hr}$. NHC was potently antiviral with an average half-maximum effective concentration $\left(\mathrm{IC}_{50}\right)$ of $0.15 \mu \mathrm{M}$ and no observed cytoxicity in similarly treated uninfected cultures across the dose range (50\% cytotoxic concentration, $\mathrm{CC}_{50},>10 \mu \mathrm{M}$ ) (Fig. 1A). The therapeutic index for $\mathrm{NHC}$ was $>100$. Using a clinical isolate of SARS-CoV2 (2019-nCoV/USA-WA1/2020), we performed antiviral assays in African green monkey kidney (Vero) cells and found $\mathrm{NHC}$ was potently antiviral with an $\mathrm{IC}_{50}$ of $0.3 \mu \mathrm{M}$ and $\mathrm{CC}_{50}$ of $>10 \mu \mathrm{M}$ (Fig. 1B). We then determined the antiviral activity of NHC against SARS-CoV-2 in the Calu-3 cells through the measurement of infectious virus production and viral genomes. We observed a dose-dependent reduction in virus titers (Fig. 1C) with an $\mathrm{IC}_{50}$ of $0.08 \mu \mathrm{M}$. Viral genomic RNA was quantitated in clarified supernatants by qRT-PCR (Fig. 1D). Like the effect on infectious titers, we found a dosedependent reduction in viral genomic RNA and a similar calculated $\mathrm{IC}_{50}$ of $0.09 \mu \mathrm{M}$. Collectively, these data demonstrate that NHC is potently antiviral against two genetically distinct emerging CoV.

NHC is highly active against SARS-CoV-2, MERS-CoV, and SARS-CoV in primary human airway epithelial cell cultures

To determine if NHC would be similarly antiviral in primary human cells, we performed a series of studies in primary airway epithelial (HAE) cell cultures. HAE model the architecture and cellular complexity of the conducting airway and are readily infected by multiple human and zoonotic CoV, including SARS- and MERS-CoV (19). We first assessed cytotoxicity of NHC in HAE treated with an extended dose range for $48 \mathrm{hr}$ using quantitative PCR of cell death-related gene transcripts as our metric. NHC treatment did not appreciably alter gene expression even at doses up to $100 \mu \mathrm{M}$ (fig. S1). We then sought to determine if NHC would inhibit clinical isolate SARS-CoV-2 replication in HAE. We observed a dose dependent reduction in SARS-CoV-2 infectious virus production (Fig. 2A). In MERS-CoV infected HAE, NHC substantially reduced virus production with maximal titer reduction of $>5 \operatorname{logs}$ at $10 \mu \mathrm{M}$ (average $\mathrm{IC}_{50}=0.024 \mu \mathrm{M}$ ), which correlated with reduced genomic (ORF1) and subgenomic (ORFN) RNA in paired samples (Fig. 2B). We observed similar trends in titer reduction $\left(>3 \log\right.$ at $10 \mu \mathrm{M}$, average $\left.\mathrm{IC}_{50}=0.14 \mu \mathrm{M}\right)$ and in copies of genomic and subgenomic RNA in SARS-CoV- infected HAE (Fig. 2C). Thus, NHC was potently antiviral against SARS-CoV-2, MERS-CoV and SARS-CoV in primary human epithelial cell cultures without cytotoxicity.

\section{NHC is effective against remdesivir (RDV)-resistant vi- rus and multiple distinct zoonotic CoV}

$\mathrm{CoV}$ are taxonomically divided into multiple genogroups (alpha, beta, gamma, delta) but human-infecting CoV are found in only the alpha and beta subgroups thus far (Fig. 3A). There is high sequence conservation in the RNA-dependent RNA polymerase (RdRp, nsp12) across CoV (Fig. 3A). For example, the RdRp of SARS-CoV-2 has $99.1 \%$ similarity and $96 \%$ amino acid identity to that of SARS-CoV (Fig. 3A). To gain insight into structural conservation of RdRp across the CoV family, we modeled the variation reflected in the RdRp dendrogram in Fig. 3A onto the structure of the SARS-CoV RdRp (20) (Fig. $3 \mathrm{~B})$. The core of the RdRp molecule and main structural motifs that all RdRp harbor (Fig. 3B and fig. S2) are highly conserved among CoV including SARS-CoV-2. We previously reported that $\mathrm{CoV}$ resistance to another broad spectrum nucleoside analog, RDV, was mediated by RdRp residues F480L and V557L in a model coronavirus mouse hepatitis virus (MHV) and in SARS-CoV, resulting in a 5-fold shift in $\mathrm{IC}_{50}$ (Fig. 3C)(21). Consequently, we tested whether RDV resistance mutations in MHV conferred cross-resistance to NHC. In fact, the two RDV resistance mutations, alone or together, conferred increased sensitivity to inhibition by NHC (Fig. 3D). As our previous studies have demonstrated a high genetic barrier to NHC for VEEV, influenza and CoV (14-16), the lack of cross-resistance further suggests that NHC and RDV may select for exclusive and mutually sensitizing resistance pathways.

To explore the breadth of antiviral efficacy against zoonotic $\mathrm{CoV}$, we performed antiviral assays in HAE with three 
zoonotic Bat-CoV: SHC014, HKU3, and HKU5. Closely related to the beta $2 \mathrm{~b}$ SARS-CoV, Bat-CoV SHC014 is capable of replicating in human cells without adaptation(11), suggesting its potential for zoonotic emergence into humans. The more distantly related SARS-like beta $2 \mathrm{~b} \mathrm{CoV}$, recombinant Bat-CoV HKU3, has a modified receptor binding domain to facilitate growth in cell culture (22). Lastly, Bat-CoV HKU5 is a MERSlike beta $2 \mathrm{c} \mathrm{CoV}$ (23). NHC diminished infectious virus production and the levels of genomic/subgenomic viral RNA in HAE in a dose-dependent manner for all three Bat-CoVs (Fig. 4). Therefore, the antiviral activity of NHC was not limited by natural amino acid variation in the RdRp, which among the group $2 \mathrm{~b}$ and group $2 \mathrm{c} \mathrm{CoV}$ can vary by almost $20 \%$. Moreover, these data suggest that if another SARS- or MERS-like virus were to spillover into humans in the future, they would likely be susceptible to the antiviral activity of NHC.

\section{NHC antiviral activity is associated with increased viral mutation rates}

It has recently been shown that NHC treatment increases the mutation rate in viral genomic RNA of RSV (24), VEEV (14), influenza (24), and our previous study used RNA seq to show that overall transition mutation frequency is increased during NHC treatment of MHV and MERS-CoV during infection in continuous cell lines(16). We sought to determine if NHC would increase the mutation frequency during MERS-CoV infection in human primary HAE. Using MERS-CoV-infected HAE treated with either vehicle or a dose range of NHC or RDV, we show that both drugs reduced virus titers in a dosedependent manner (Fig. 5A). We then used a highly-sensitive high-fidelity deep sequencing approach (Primer ID NGS), which uses barcoded degenerate primers and Illumina indexed libraries to determine accurate mutation rates on viral RNA production (25). Using this approach, we analyzed a 538 bp region of viral genomic RNA in nonstructural protein 15 (nsp15). The error rates (\#mutations/10,000 bases) in vehicle(0.01) or RDV- (0.01) treated cultures were very low. RDV is reported to act via chain termination of nascent viral RNA, and thus the low error rates in RDV-treated cultures are in line with the proposed MOA (26). In contrast, the error rate was significantly increased in NHC-treated MERS-CoV RNA in a dose-dependent manner (Two-way ANOVA with Dunnett's multiple comparison test; 10-fold increase at $10 \mu \mathrm{M}, \mathrm{P}$ $<0.0001$ at 24 and $48 \mathrm{hpi} ; 5$-fold increase at $1 \mu \mathrm{M}, \mathrm{P}<0.0001$ at $24 \mathrm{hpi}$ and $\mathrm{P}=0.0015$ at $48 \mathrm{hpi}$ ) (Fig. $5 \mathrm{C}$ ). The magnitude of the error rate in NHC-treated cultures correlated with virus titer reduction. At $48 \mathrm{hpi}$ the respective error rate and virus titer was 0.015 and $3.96 \mathrm{E}+06 \mathrm{pfu} / \mathrm{mL}$ for vehicle treatment, 0.045 and $2.86 \mathrm{E}+04 \mathrm{pfu} / \mathrm{mL}$ with $1 \mu \mathrm{M}$ NHC; and 0.090 and $1.5 \mathrm{E}+02 \mathrm{pfu} / \mathrm{mL} 10 \mu \mathrm{M}$ NHC. Thus, with $1 \mu \mathrm{M}$ NHC a 3fold increase in error rate resulted in a 138 -fold decrease in virus titer, while with $10 \mu \mathrm{M}$ NHC a 6 -fold increase in error rate resulted in a 26,000-fold decrease in virus titer.
We then examined the mutational spectra induced by NHC, which can be incorporated into viral RNA as a substitution for either cytosine (C) or uracil (U). RNA-mutagenic antivirals may incorporate in both nascent negative and positive sense RNA during genome replication (Fig. 5D). Adenine-to-guanine (A-to-G) and uracil-to-cytosine (U-to-C) transitions were enriched in MERS-CoV genomic RNA in an NHC dose-dependent manner (Fig. 5E). Collectively, these data used high-fidelity sequence analysis to demonstrate a specific enrichment for A:G and C:U transitions in MERSCoV RNA after NHC treatment of primary HAE cell cultures.

\section{Therapeutic EIDD-2801 reduces SARS-CoV replication and pathogenesis}

Given the promising antiviral activity of NHC in vitro, we next evaluated its in vivo efficacy using EIDD-2801, an orally bioavailable prodrug of NHC ( $\beta-\mathrm{D}-\mathrm{N}^{4}$-hydroxycytidine- $5^{\prime}$-isopropyl ester), designed for improved in vivo pharmacokinetics and oral bioavailability in humans and non-human primates (15). Importantly, the plasma profiles of NHC and EIDD-2801 are similar in mice following oral delivery (15). We first performed a prophylactic dose escalation study in C57BL/6 mice where we orally administered vehicle (10\% PEG, 2.5\% Cremophor RH40 in water) or 50, 150, or 500 $\mathrm{mg} / \mathrm{kg}$ EIDD-2801 $2 \mathrm{hr}$ prior to intranasal infection with $5 \mathrm{E}+04$ PFU of mouse-adapted SARS-CoV (SARS-MA15), and then vehicle or drug every 12 hours thereafter. Beginning on 3 days post-infection (dpi) and through the end of the study, body weight loss compared to vehicle treatment was significantly diminished $(50 \mathrm{mg} / \mathrm{kg})$ or prevented $(150,500 \mathrm{mg} / \mathrm{kg})$ with EIDD-2801 prophylaxis (Two-way ANOVA with Dunnett's multiple comparison test, $\mathrm{P}<0.0001$ ) (fig. S3A). Lung hemorrhage was also significantly reduced 5 dpi with 500 $\mathrm{mg} / \mathrm{kg}$ EIDD-2801 treatment (Kruskal-Wallis Test, $\mathrm{P}=0.010$, fig. S3B). Interestingly, there was a dose-dependent reduction in SARS-CoV lung titer (median titers: $50 \mathrm{mg} / \mathrm{kg}=7 \mathrm{E}+03$ $\mathrm{pfu} / \mathrm{mL}, 150 \mathrm{mg} / \mathrm{kg}=2.5 \mathrm{E}+03 \mathrm{pfu} / \mathrm{mL}, 500 \mathrm{mg} / \mathrm{kg}=50$ $\mathrm{pfu} / \mathrm{mL}$, vehicle $=6.5 \mathrm{E}+04 \mathrm{pfu} / \mathrm{mL}$ ) with significant differences (Kruskal-Wallis with Dunn's multiple comparisons test) among the vehicle, $150 \mathrm{mg} / \mathrm{kg}(\mathrm{P}=0.03)$ and $500 \mathrm{mg} / \mathrm{kg}$ $(\mathrm{P}=0.006)$ groups. Thus, prophylactic orally administered EIDD-2801 was robustly antiviral and able to prevent SARS$\mathrm{CoV}$ replication and disease.

Since only the $500 \mathrm{mg} / \mathrm{kg}$ group significantly diminished weight loss, hemorrhage and reduced lung titer to near undetectable levels, we tested this dose under therapeutic treatment conditions to determine if EIDD-2801 could improve the outcomes of an ongoing $\mathrm{CoV}$ infection. As a control, we initiated oral vehicle or EIDD-2801 2 hours prior to infection with $1 \mathrm{E}+04 \mathrm{pfu}$ SARS-MA15. For therapeutic conditions, we initiated EIDD-2801 treatment 12, 24, or 48 hours after infection. After initiating treatment, dosing for all groups was performed every 12 hours for the duration of the study. Both 
prophylactic treatment initiated 2 hours prior to infection and therapeutic treatment initiated 12 hours after infection significantly (Two-way ANOVA with Tukey's multiple comparison test) prevented body weight loss following SARS-CoV infection on 2 dpi and thereafter $(-2$ hours: $\mathrm{P}=0.0002$ to $<0.0001$; +12 hours: $\mathrm{P}=0.0289$ to $<0.0001$ ) as compared to vehicle treated animals (Fig. 6A). Treatment initiated $24 \mathrm{hpi}$ also significantly reduced body weight loss (3-5 dpi, P $=0.01$ to $<0.0001$ ) although not to the same degree as the earlier treatment initiation groups. When initiated $48 \mathrm{hpi}$, body weight loss was only different from vehicle on 4 dpi $(\mathrm{P}=$ 0.037, Fig. 6A). Therapeutic EIDD-2801 significantly (Kruskal-Wallis with Dunnett's multiple comparison test) reduced lung hemorrhage when initiated up to 24 hours after infection $(-2,+12$, and +24 hours $\mathrm{P}<0.0001)$ mirroring the body weight loss phenotypes (Fig. 6B). Interestingly, all EIDD-2801 treated mice had significantly (Kruskal-Wallis with Dunnett's multiple comparison test) reduced viral loads in the lungs even in the +48 hours group (All $\mathrm{P}<0.0001$, Fig. $6 \mathrm{C}$ ), which experienced the least protection from body weight loss and lung hemorrhage. We also measured pulmonary function via whole body plethysmography (WBP). In Fig. 6D, we show the WBP enhanced pause (PenH) metric, which is a surrogate marker for bronchoconstriction or pulmonary obstruction (27), was significantly (Two-way ANOVA with Dunnett's multiple comparison test) improved throughout the course of the study if treatment was initiated up to 12 hours after infection (-2 hours: $2 \mathrm{~d}$ pi to $5 \mathrm{dpi}, \mathrm{P}<0.0001$ to $0.019,+12$ hours: $2 \mathrm{dpi}$ to $5 \mathrm{dpi}, \mathrm{P}<0.0001$ to 0.0192$)$ although the +24 hours group showed sporadic improvement as well ( $3 \mathrm{dpi} \mathrm{P}=0.002)$ (Fig. $6 \mathrm{D})$. Lastly, we blindly evaluated hematoxylin and eosinstained lung tissue sections for histological features of ALI using two different and complementary scoring tools (18), which show that treatment initiated up to +12 hours significantly reduced ALI (Kruskal-Wallis with Dunn's multiple comparison test) (American Thoracic Society (ATS) Lung Injury Score: -2 hours $P=0.0004,+12$ hours $P=0.0053$, Diffuse alveolar damage (DAD) Score: -2 hours $P=0.0015,+12$ hours $\mathrm{P}=0.0004$, Fig. 6E). Altogether, therapeutic EIDD-2801 was potently antiviral against SARS-CoV in vivo but the degree of clinical benefit was dependent on the time of initiation postinfection.

\section{EIDD-2801 prophylactic and therapeutic efficacy corre- lates with increased MERS-CoV mutation rate}

After obtaining promising in vivo efficacy data with SARS$\mathrm{CoV}$, we investigated whether EIDD-2801 would be effective against MERS-CoV. As the murine ortholog of the MERS-CoV receptor, dipeptidyl peptidase 4 (DPP4), does not support viral binding and entry, all in vivo studies were performed in genetically modified mice encoding a murine DPP4 receptor encoding two human residues at positions 288 and 330 (hDPP4 288/330 mice)(18, 28). Similar to our SARS-CoV data, all doses of prophylactic EIDD-2801 (50, 150 and $500 \mathrm{mg} / \mathrm{kg}$ ) protected hDPP4 288/330 mice (fig. S4) from significant body weight loss (Two-way ANOVA with Dunnett's multiple comparison test, $\mathrm{P}=0.03$ to $<0.0001$ ), lung hemorrhage (KruskalWallis with Dunn's multiple comparison test, $\mathrm{P}=0.01$ to $<0.0001$ ), and virus replication which was undetectable (Kruskal-Wallis with Dunn's multiple comparison test, $\mathrm{P}<$ 0.0001) regardless of drug dose following intranasal infection with 5E+04 PFU mouse-adapted MERS-CoV (fig. S4).

We then evaluated the therapeutic efficacy EIDD-2801 following the promising results of our prophylactic studies. Similar to our SARS-CoV study, EIDD-2801 treatment administered before or 12 hours after intranasal mouseadapted MERS-CoV infection (5E+04 PFU) prevented body weight loss from 2 through 6 dpi (Two-way ANOVA with Tukey's multiple comparison test, Fig. $7 \mathrm{~A}, \mathrm{P}=0.02$ to $<0.0001$ ) and lung hemorrhage on $6 \mathrm{dpi}$ (Kruskal-Wallis with Dunn's multiple comparison test, $\mathrm{P}=0.0004$ to $<0.0001$, Fig. $7 \mathrm{~B})$, but treatment initiated 24 or 48 hours did not offer similar protection. Unlike body weight loss and lung hemorrhage data which varied by treatment initiation time, virus lung titer on 6 dpi was significantly reduced to the limit of detection in all treatment groups (Kruskal-Wallis with Dunn's multiple comparison test, Fig. 7C, $\mathrm{P}<0.0001)$. Interestingly, when viral genomic RNA was quantified in paired samples of lung tissue, EIDD-2801 significantly reduced quantities of viral RNA (One-way ANOVA with Dunnett's multiple comparison test, $\mathrm{P}<0.0001$ to 0.017 ) in an initiation time-dependent manner for all groups except for +48 hours (Fig. 7D). The discrepancy among infectious titers and viral RNA suggests that accumulated mutations render the particles non-infectious and undetectable by plaque assay, consistent with the MOA. To gauge the effect of EIDD-2801 treatment on lung function, we assessed pulmonary function by WBP. Mirroring the body weight loss data, normal pulmonary function was only observed in groups where treatment was initiated prior to or 12 hours after infection (Two-way ANOVA with Tukey's multiple comparison test, -2hr: $\mathrm{P}<0.00013 \mathrm{dpi}, \mathrm{P}=0.00024 \mathrm{dpi}$, +12 hr: $\mathrm{P}<0.00013 \mathrm{dpi}, \mathrm{P}=0.00084 \mathrm{dpi}$, Fig. 7E). Collectively, these data demonstrate that NHC prodrug, EIDD-2801, robustly reduces MERS-CoV infectious titers, viral RNA, and pathogenesis under both prophylactic and early therapeutic conditions.

To study the molecular mechanisms associated with drug performance in vivo, we investigated the correlation between infectious virus production and EIDD-2801-mediated mutagenesis of MERS-CoV RNA under therapeutic treatment conditions. Using Primer ID NGS, we measured the mutation rates of both viral genomic RNA (non-structural protein 10, nsp10) and host interferon stimulated gene 15 (ISG15) mRNA, a highly up-regulated innate immune-related gene after MERS-CoV infection (Fig. 7F). Primer ID NGS measures the 
mutational frequency in single RNA molecules, each of which are represented by a single template consensus sequence (TCS) (25). Viral TCS were significantly reduced (Two-way ANOVA with Tukey's multiple comparison test, -2 hours $\mathrm{P}$ $<0.0001,+12$ hours $\mathrm{P}=0.0001,+24$ hours $\mathrm{P}=0.02)$ in a treatment initiation time-dependent manner (Fig. 7G) similar to viral genomic RNA measured by qRT-PCR. In contrast, the numbers of ISG15 TCS were similar $(\mathrm{P}=0.2$ to 0.8 ) for all groups indicating that neither vehicle nor drug treatment significantly affected the levels of or mutated ISG15 mRNA transcripts (Fig. 7G). Similar to our TCS data in Fig. 6G, the total error rate in viral nsp10 was significantly increased (Two-way ANOVA with Tukey's multiple comparison test) in groups where treatment was initiated prior to (-2 hours, median error rate $=10.5$ errors $/ 10,000$ bases, $\mathrm{P}<0.0001)$ and up to 24 hours post infection (12 hours, median error rate $=8.2 \mathrm{er}-$ rors $/ 10,000$ bases, $\mathrm{P}<0.0001 ;+24$ hours, median error rate $=5.4$ errors $/ 10,000$ bases, $\mathrm{P}=0.0003$ ) but the error rates in ISG15 remained at baseline for all groups (Fig. 7H). In addition, nucleotide transitions observed in MERS-CoV genomes in vitro, were also observed in vivo in groups where treatment was initiated prior to and up to 12 hours post infection (Twoway ANOVA with Tukey's multiple comparison test, $\mathrm{P}=$ 0.0003 to $<0.0001$ ) (Fig. 7I). Importantly, these transitions were not observed in host ISG15 mRNA (Fig. 7I). Lastly, the EIDD-2801 dose-dependent mutagenesis of viral RNA correlated with an increase in codon change frequency, including stop codons, in mice where treatment was initiated 12 hours or before (Two-way ANOVA with Tukey's multiple comparison test, vehicle median $=3.4 ;-2 \mathrm{hr}$ median $=22.8, \mathrm{P}=0.0035$; +12 hours median $=20.0, \mathrm{P}=0.0004$, Fig. $7 \mathrm{~J})$. Thus, approximately $20 \%$ of the mutations observed in the -2 hours and +12 hours groups resulted in a codon change and alteration of the nsp10 protein sequence. When extrapolating our results from nsp10 to the entirety of the 30kb MERS-CoV genome, EIDD-2801 likely causes between 15 (+24 hours treatment) and 30 (-2 hours treatment) mutations per genome, $10-20 \%$ of which result in amino acid coding changes. Altogether, our data demonstrates that EIDD-2801-driven mutagenesis correlates well with the reductions in viral load, strongly suggestive of an error catastrophe-driven mechanism of action under therapeutic conditions.

\section{DISCUSSION}

In the past 20 years, three novel human coronaviruses have emerged $(29,30)$. The group $2 \mathrm{~b}$ SARS-like CoV represent an existential and future threat to global health as evidenced by the emergence of SARS-CoV and SARS-CoV-2. Zoonotic SARS-like bat CoV strains can use human angiotensin-converting enzyme 2 (ACE2) receptors, grow well in primary human airway cells, and vary by as much as $25 \%$ in key therapeutic and vaccine gene targets $(11,31)$. Thus, to address the current public health emergency of COVID-19 and to maximize pandemic preparedness in the future, broad-based vaccines and therapeutics, which are active against the higher risk RNA virus families prone to emergence, are desperately needed.

Small molecule antivirals can exert their antiviral effect through multiple mechanisms including blocking viral entry, inhibiting a virally encoded enzyme, blocking virus particle formation, or targeting a host factor required for replication (32). Multiple direct acting antivirals are currently under evaluation in randomized control trials to treat COVID-19 including hydroxychloroquine, remdesivir, lopinavir/ritonavir(33-35). Here, we report the broad-spectrum antiviral activity of NHC and its orally bioavailable prodrug EIDD2801, against SARS-CoV, MERS-CoV, and the current pandemic strain SARS-CoV-2 in primary human airway epithelial cells. In addition to $\mathrm{CoV}, \mathrm{NHC}$ is broadly active against multiple genetically distinct viruses including VEE, influenza A and B, Ebola, and Chikungunya viruses (13-16, 19, 21, 24, 3638 ). Here, we show that prophylactic and therapeutic EIDD2801 significantly reduced lung viral loads and improved pulmonary function in mouse models of both SARS- and MERSCoV pathogenesis. Although the improvement in both SARSand MERS-CoV outcomes diminished with the delay of treatment initiation time, it is important to note that the kinetics of disease in mice are compressed as compared to that in humans. Whereas SARS- and MERS-CoV lung titers peak on 1-2 dpi in mice concurrent with the onset of clinical signs and notable damage to the lung epithelium, in humans this occurs 7-10 days after the onset of symptoms $(19,28,39,40)$. Thus, in mice, the window within which to treat emerging $\mathrm{CoV}$ infection prior to peak replication is compressed (e.g., 24-48 hours). As with oseltamivir treatment for influenza which fails to provide a protective effect if administered $>5$ days after the onset of symptoms, the window in which to treat COVID-19 patients prior to peak virus replication is likely during the first week of symptoms when pharyngeal shedding is at its highest $(41,42)$. However, virus replication and shedding may continue for several weeks in the most severe COVID-19 patients(34). Thus, early intervention with an antiviral like EIDD-2801 is likely to provide the most clinical benefit although there may opportunities in severe patients where the duration of virus replication may be extended. Our current study is clearly limited by the lack of in vivo efficacy testing with SARS-CoV-2. Currently, robust mouse models that recapitulate the SARS-CoV-2 pathogenesis observed in humans do not yet exist due to a noted virus spike glycoprotein and mouse ACE2 receptor incompatibility complicating the evaluation of medical countermeasures $(43,44)$. In addition, SARS-CoV and MERS-CoV, SARS-CoV-2 disease severity increases with increasing age. Our studies are limited by the lack of drug efficacy testing in $\mathrm{CoV}$ aged mouse models that 
recapitulate the age-related increase in pathogenesis observed in humans(45). The data provided in this manuscript suggest that EIDD-2801 should be quickly evaluated in primate models of human disease, using immediate models for MERS-CoV and SARS-CoV pathogenesis or newly described cynomolgus and rhesus macaque models for SARS-CoV-2 (4649).

For VEE and influenza, NHC/EIDD-2801 exerts its antiviral activity on the RNA-dependent RNA polymerase leading to error catastrophe by inducing an error rate of replication that surpasses the error threshold allowed to sustain a virus population $(14,15)$. This process occurs when NHC is incorporated during RNA synthesis then subsequently misread thus increasing mutation rates. Therefore, for $\mathrm{CoV}$, the NHC MOA would appear less likely to be affected by the RNA proofreading activity encoded by the nsp14 exonuclease function that otherwise limits misincorperation (50). Here, we present data using Primer ID NGS to quantitate the frequency and identity of the mutational spectra in the MERSCoV genome in both drug-treated primary human airway cells and in mice at single genome resolution. As CoV are positive sense RNA viruses that replicate through a negative sense RNA intermediate, NHC incorporation as a $\mathrm{C}$ or a $\mathrm{U}$ can occur in both polarities of RNA. We found increased nucleotide transitions (A to $\mathrm{G}, \mathrm{G}$ to $\mathrm{A}, \mathrm{C}$ to $\mathrm{U}, \mathrm{U}$ to $\mathrm{C}$ ) consistent with those reported after influenza and VEE infections (14, 15). Under identical conditions, RDV did not alter the mutation rate in MERS-CoV genomic RNA, supporting its reported mechanism of action as a chain terminator of viral RNA synthesis (26). In primary human lung cell cultures and mice infected with MERS-CoV, the NHC mutation rates inversely correlated with a reduction in infectious virus. In addition, we found a positive correlation between increased mutation rates and the frequency of nonsynonymous mutations and the degree of therapeutic efficacy in mice. To explore the potential off-target effect in host mRNA which may contribute to drug toxicity, we also examined the impact of NHC treatment on ISG15 transcripts, a gene highly induced following MERS-CoV infection. Although ISG15 transcripts are present in great abundance, an accumulation of mutations was not observed in ISG15 in this model even at $500 \mathrm{mg} / \mathrm{kg}$ dosing. These data also support previous studies using RNAseq to demonstrate that the model coronavirus MHV displayed increased mutation frequencies following NHC treatment in vitro (16). With regard to nucleic acid specificity, ribonucleotides are efficiently removed from eukaryotic cell DNA; therefore, treating a viral infection with a mutagenic ribonucleoside analog should show a selectivity for incorporation into the viral genome and not be efficient at being incorporated into and inducing mutations into host cell DNA (51). All together, these data strongly support the notion that EIDD-2801 and its active nucleoside analog NHC exert their antiviral effect through the induction of error catastrophe in the targeted virus. While our data suggest that the MERS-CoV nsp14 proofreading activity appeared ineffective against NHC in vitro and EIDD-2801 in vivo, future studies should investigate the antiviral activity of NHC in the presence or absence of the nsp14 proofreading activity, as loss of this activity increased the sensitivity of $\mathrm{MHV}$ and SARS-CoV replication to RDV treatment (50).

Together, our data support the continued development of EIDD-2801 as a potent broad spectrum antiviral that could be useful in treating contemporary, newly emerged and emerging coronavirus infections of the future.

\section{MATERIALS AND METHODS}

\section{Study Design}

The primary goal of this study was to determine the antiviral activity of the nucleoside analog NHC (EIDD-1931) against multiple emerging $\mathrm{CoV}$ in vitro and antiviral efficacy of its prodrug, EIDD-2801, in mouse models of CoV pathogenesis. Coupling cell lines and primary HAE cell cultures, we evaluated the antiviral activity of NHC against the three most recently emerged human CoV: SARS-CoV, MERS-CoV, and SARS-CoV-2. For both SARS-CoV and MERS-CoV, the data presented for HAE studies are representative of those from 23 separate human donors. For SARS-CoV-2, the HAE were from a single human donor. We evaluated drug cytotoxicity in both Calu-3 2B4 and HAE cell cultures. Calu-3 and the SARS-CoV and MERS-CoV HAE studies were performed in biological triplicate. HAE studies with SARS-CoV-2 and the SARS- and MERS-like bat CoV were performed with two wells per condition. Drug effects were measured relative to vehicle controls in vitro and comparisons in vivo were performed to vehicle controls. We also aimed to determine the antiviral efficacy of EIDD-2801 in mouse models of $\mathrm{CoV}$ pathogenesis. These studies were intended to provide the preclinical data to justify nonhuman primate studies and human clinical trials. Mice were age- and sex-matched and randomly assigned into groups before infection and treatment. Pathology was scored blinded by a board-certified veterinary pathologist. Primary data for all studies are provided in data file S1.

\section{Ethics regulation of laboratory animals}

Efficacy studies were performed in animal biosafety level 3 facilities at UNC Chapel Hill. All work was conducted under protocols approved by the Institutional Animal Care and Use Committee at UNC Chapel Hill (IACUC protocol \#16-284) according to guidelines set by the Association for the Assessment and Accreditation of Laboratory Animal Care and the U.S. Department of Agriculture.

\section{Compounds}

The parental compound $\beta-\mathrm{D}-\mathrm{N}^{4}$-hydroxycytidine (NHC, all in vitro studies) and its prodrug EIDD-2801 (all in vivo studies) was supplied by Emory University Institute for Drug 
Discovery (EIDD). NHC was supplied as a $10 \mathrm{mM}$ stock in DMSO and EIDD-2801 as a solid and solubilized in vehicle containing 10\% PEG400, 2.5\% Cremophor RH40 in water $(10 / 2.5 / 87.5 \%$, all v/v) prior to use. RDV was solubilized in $100 \%$ DMSO and provided by Gilead Sciences, Inc as previously described $(18,19)$.

\section{Cell cultures}

At UNC, the human lung epithelial cell line Calu-3 2B4 cells was maintained in Dulbecco's modified Eagle's medium (DMEM, Gibco), 20\% fetal bovine serum (Hyclone) and 1x antibiotic/antimycotic (Gibco). At Vanderbilt University Medical Center (VUMC), Calu-3 2B4 were propagated in DMEM supplemented with $20 \%$ FBS (Gibco), $100 \mathrm{U} / \mathrm{ml}$ penicillin and streptomycin (Gibco), and $0.25 \mu \mathrm{M}$ amphotericin B (Corning). At VUMC, VeroE6 cells were cultured in DMEM supplemented with 10\% FBS (Gibco), $100 \mathrm{U} / \mathrm{ml}$ penicillin and streptomycin (Gibco), and $0.25 \mu \mathrm{M}$ amphotericin B (Corning). At UNC, VeroE6 cells were cultured in DMEM supplemented with 10\% Fetal Clone II (Hyclone) and 1x antibiotic/antimycotic (Gibco). Murine delayed brain tumor (DBT) cells were maintained in DMEM supplemented with 10\% FBS (Gibco), $100 \mathrm{U} / \mathrm{ml}$ penicillin and streptomycin (Gibco), and $0.25 \mu \mathrm{M}$ amphotericin B (Corning). Primary human airway epithelial (HAE) cell cultures were obtained from the Tissue Procurement and Cell Culture Core Laboratory in the Marsico Lung Institute/Cystic Fibrosis Research Center at UNC and are described more thoroughly below (52).

\section{Virus strains}

Except for SARS-CoV-2, all viruses used for these studies were derived from infectious clones and isolated as previously described (53). SARS-CoV-2 clinical isolate was obtained at VUMC and UNC from the CDC (2019-nCoV/USA-WA1/2020 strain, GenBank accession no. MN985325.1) and passaged twice in Vero E6 cells at each respective institution to create a passage 5 working stock (54). Virus strains for in vitro experiments include SARS-CoV expressing the green fluorescent protein (GFP) in place of open reading frames $7 \mathrm{a} / \mathrm{b}$ (ORF7a/b, SARS-GFP)(53), bat-spike receptor binding domain (Bat-SRBD)(22), a chimeric CoV strain derived from the HKU3 SARS-like bat coronavirus genomic sequence that has the wild type (Urbani SARS-CoV strain) RBD in the HKU3 spike gene to allow for virus replication in non-human primate cell lines and HAE cultures, SHC014 SARS-like bat coronavirus (11), MERS-CoV expressing nanoluciferase in the place of ORF3 (MERS-nLUC)(19), and MERS-CoV expressing the red fluorescent protein gene in the place of ORF 5 (RFP, MERS-RFP)(55). The virus stock utilized for MERS-CoV in vivo studies was derived from a plaque-purified isolate of the mouse-adapted MERS-CoV p35C4 strain (56). The virus stock utilized for SARS-CoV in vivo studies was derived from the infectious clone of the mouse-adapted SARS-CoV MA15 (MA15) strain (57). All work with MHV was performed using the recombinant WT strain MHV-A59 (GenBank accession no. AY910861)(58).

\section{In vitro antiviral activity experiments}

MERS-CoV nLUC in Calu-3: At 48 hours prior to infection, Calu-3 2B4 cells were plated in a 96-well black-walled clear bottom plate at $5 \times 10^{4}$ cells/well. A $10 \mathrm{mM}$ stock of $\mathrm{NHC}$ was serially diluted in $100 \%$ DMSO in 3-fold increments to obtain a ten-point dilution series. MERS-nLUC was diluted in DMEM supplemented with 10\% FBS, and 1\% Antibiotic-Antimycotic to achieve a multiplicity of infection (MOI) of 0.08 . Cells were infected and concurrently treated with NHC in triplicate per drug dilution for $1 \mathrm{hr}$, after which viral inoculum was aspirated, cultures were rinsed once and fresh medium containing drug or vehicle was added. At 48 hours post infection, nanoluciferase expression as a surrogate for virus replication was quantitated on a Spectramax plate reader (Molecular Devices) according to the manufacturer's instructions (Promega, NanoGlo). For the $100 \%$ inhibition control, diluted MERS-nLUC was exposed to short-wave UV light (UVP, LLC) for 6 min to inhibit the ability of the virus to replicate. For the $0 \%$ inhibition control, cells were infected in the presence of vehicle only. DMSO was kept constant in all conditions at $0.05 \%$. Values from triplicate wells per condition were averaged and compared to controls to generate a percent inhibition value for each drug dilution. The $\mathrm{IC}_{50}$ value was defined as the concentration at which there was a $50 \%$ decrease in luciferase expression. Data were analyzed using GraphPad Prism 8.0. The $\mathrm{IC}_{50}$ values were calculated by nonlinear regression analysis using the dose-response (variable slope) equation (four parameter logistic equation): $\mathrm{Y}=$ Bottom $+($ Top-Bottom $) /\left(1+10^{\wedge}((\log I C 50-X) *\right.$ HillSlope $\left.)\right)$. To measure cell viability to determine if there was any $\mathrm{NHC}$ induced cytotoxicity, Calu-3 2B4 cells were plated and treated with NHC only as described above. Cells were exposed to the same ten-point dilution series created for the in vitro efficacy studies. As above, 0.05\% DMSO-treated cells served as the 0\% cytotoxicity control. Wells without cells served as the $100 \%$ cytotoxic positive control. After 48 hours, cell viability was measured on a Spectramax (Molecular Devices) via Cell-Titer Glo Assay (Promega) according to the manufacturer's protocol. Similar data were obtained in three independent experiments.

SARS-CoV-2 in Calu-3:_Calu-3 2B4 cells were adsorbed with MOI 0.1 PFU/cell of SARS-CoV-2 (2019-nCoV/USA$\mathrm{WA1} / 2020$ strain) at $37^{\circ} \mathrm{C}$. Plates were manually rocked every $10 \mathrm{~min}$ to redistribute the inoculum. After $30 \mathrm{~min}$, virus inoculum was removed, cells were washed with Phosphate buffered saline (PBS) once to remove unbound virus, medium containing NHC or vehicle control (DMSO) was added back onto the cells, and cells were incubated for 72 hours at $37^{\circ} \mathrm{C}$.

$S A R S-C o V-2$ in Vero E6: Vero E6 cells were plated at 20,000 cells/well in a 96 -well plate. $24 \mathrm{hr}$ later, medium 
containing a dose response of NHC was added concurrent with SARS-CoV-2 (2019-nCoV/USA-WA1/2020 strain) at an MOI of 0.05 . 48 hours post infection, cell viability was measured by CellTiter Glo assay.

$S A R S-C o V, M E R S-C o V$, and SARS-CoV-2 in HAE: Human tracheobronchial epithelial cells provided by Dr. Scott Randell were obtained from airway specimens resected from patients undergoing surgery under University of North Carolina Institutional Review Board-approved protocols (\#03-1396) by the Cystic Fibrosis Center Tissue Culture Core. Primary cells were expanded to generate passage 1 cells and passage 2 cells were plated at a density of 250,000 cells per well on Transwell-COL (12mm diameter) supports (Corning). Human airway epithelium cultures (HAE) were generated by provision of an air-liquid interface for 6 to 8 weeks to form welldifferentiated, polarized cultures that resembled in vivo pseudostratified mucociliary epithelium (59). At 48 hours prior to infection the apical surface of the culture was washed with $500 \mu \mathrm{L}$ PBS for 1.5 hours at $37^{\circ} \mathrm{C}$ and the cultures moved into fresh air liquid interface (ALI) media. Immediately prior to infection, apical surfaces were washed twice to remove accumulated mucus with $500 \mu \mathrm{L}$ of PBS with each wash lasting 30 min at $37^{\circ} \mathrm{C}$ and HAE cultures were moved into ALI media containing various concentrations of NHC ranging from 10 $\mu \mathrm{M}$ to $0.0016 \mu \mathrm{M}$ as indicated for each experiment (final \% DMSO < 0.05\%). Upon removing the second PBS wash, 200 $\mu \mathrm{L}$ of viral inoculum (SARS-GFP, MERS-RFP or 2019$\mathrm{nCoV} / \mathrm{USA}-\mathrm{WA1} / 2020$ strain) at an MOI of 0.5 was added to the apical surface and HAE cultures were incubated for 2 hours at $37^{\circ} \mathrm{C}$. Viral inoculum was then removed, and the apical surface of the cultures were washed three times with $500 \mu \mathrm{L}$ PBS and then incubated at $37^{\circ} \mathrm{C}$ until 48 hours post infection (hpi). For all HAE cultures, infectious virus produced was collected by washing the apical surface of the culture with $100 \mu \mathrm{L}$ PBS. Apical washes were stored at $-80^{\circ} \mathrm{C}$ until analysis and titered by plaque assay as previously described (19).

\section{qRT-PCR approach to assess cytotoxicity}

Total RNA was isolated using the Zymo Direct-zol RNA MiniPrep Kit (Zymo Research Corp.) according to the manufacturer's directions. Cells were treated with $1 \mu \mathrm{M}$ staurosporine (Sigma-Aldrich) as a positive control. First-strand cDNA was generated using Superscript III reverse transcriptase (Life Technologies). For quantification of cellular markers of toxicity/apoptosis, real-time PCR was performed using commercially validated TaqMan-based primer-probe sets (table S1) and TaqMan Universal PCR Mix (Life Technologies). Results were then normalized as described above.

\section{MERS-CoV genomic RNA qRT-PCR}

Mouse lungs were stored in RNAlater (ThermoFisher) at $80^{\circ} \mathrm{C}$ until processed via homogenization in TRIzol (Invitrogen). Total RNA was isolated using Direct-zol RNA MiniPrep kit (Zymo Research). Previously published TaqMan primers were synthesized by Integrated DNA Technologies (IDT) to quantify MERS genomic RNA (targeting orfla: Forward: $5^{\prime}$ GCACATCTGTGGTTCTCCTCTCT-3', Probe (6FAM/ZEN/IBFQ): 5 ' - TGCTCCAACAGTTACAC-3 ', Reverse: $5^{\prime}$-AAGCCCAGGCCCTACTATTAGC)(60). qRT-PCR was performed using 100ng total RNA compared to an RNA standard curve using TaqMan Fast Virus 1-Step Master Mix (ThermoFisher) on a Quant Studio 3 (Applied Biosystems).

\section{Quantification of SARS-CoV-2 viral RNA genome copy number by qRT-PCR}

Cell supernatants were harvested in TRIzol LS reagent (Invitrogen), and RNA was purified following phase separation by chloroform as recommended by the manufacturer. The RNA in the aqueous phase was collected and further purified using PureLink RNA Mini Kits (Invitrogen) according to the manufacturer's protocol. Viral RNA was quantified using one-step quantitative reverse transcription PCR (qRT-PCR) on a StepOnePlus Real-Time PCR system (Applied Biosystems) by TaqMan Fast Virus 1-Step Master Mix chemistry (Applied Biosystems). SARS-CoV-2 N gene RNA was amplified using forward (5'-GACCCCAAAATCAGCGAAAT) and reverse (5'TCTGGTTACTGCCAGTTGAATCTG) primers and probe ( $5^{\prime}$ FAM-ACCCCGCATTACGTTTGGTGGACC-BHQ1) designed by the United States Centers for Disease Control and Prevention (oligonucleotides produced by IDT, cat\# 10006606). Copy numbers were interpolated from a standard curve produced with dilutions of N gene RNA. Briefly, SARS-CoV-2-N positive control plasmid DNA (IDT, cat\# 10006625) was amplified using forward (5' TAATACGACTCACTATAGGGATGTCTGATAATGGACCCCA) and reverse (5' - TTAGGCCTGAGTTGAGTCAG) primers, resulting in a 1280 nucleotide fragment containing a $\mathrm{T} 7$ promoter. The PCR product was purified by column (Promega) and in vitro transcribed using the mMESSAGE mMACHINE T7 Transcription Kit (Invitrogen) according to the manufacturer's protocol. Transcribed RNA was purified using RNeasy mini kit (Qiagen) according to the manufacturer's protocol, and serial 10-fold dilutions were quantified as described above.

\section{Primer ID and deep sequencing}

Primer ID NGS is designed to specifically identify and remove RT-PCR mutations, while facilitating highly accurate sequence determination of single RNA molecules, because each cDNA is created with a barcoded degenerate primer (N10, $4^{10}$ combinations) from which Illumina indexed libraries are made. We used a multiplexed Primer ID library prep approach and MiSeq sequencing to investigate the presence of mutations in the viral genomes and murine mRNA. We designed cDNA primers targeting multiple regions on the viral genome and murine mRNA, each with a block of random 
nucleotides (11 bp long) as the Primer ID (25, 61) (table S2). Viral RNA was extracted using QIAamp viral RNA kit. A preamplification titration of templates was performed to estimate the amount of template to use. We used SuperScript III to make cDNA with multiplexed cDNA primers based on the regions to be sequenced. We used 41R_PID11 for the pilot sequencing and titration determination. For the MERS-CoV sequencing, we multiplexed nsp10_PID11, nsp12_PID11 and nsp14_PID11 for the cDNA reaction; for the murine mRNA sequencing, we used mixed primers of nsp10_PID11, ifit3_PID11, isg15_PID11. After bead purification, we amplified the cDNA with a mixture of forward primers (based on the described schemes) and a universal reverse primer, followed by another round of PCR to incorporate Illumina sequencing adaptors and barcodes in the amplicons. After gelpurification and quantification, we pooled 24 libraries for MiSeq 300 base paired-end sequencing. The TCS pipeline version 1.38 (https://github.com/SwanstromLab/PID) was used to process the Primer ID sequencing data and construct template consensus sequences (TCSs) to represent each individual input templates, and the sequences of each region in the pool was de-multiplexed. The RUBY package viral_seq version 1.0.6 (https://rubygems.org/gems/viral_seq) was used to calculate the mutation rate at each position. NCBI SRA Accession numbers for sequence data are as follows: PRJNA613261 (Fig. 5) and PRJNA613454 (Fig. 7).

\section{In vivo experiments}

We performed 4 mouse studies to evaluate the in vivo efficacy of the NHC prodrug (EIDD-2801). First, we performed prophylactic dose escalation studies for both SARS- and MERS-CoV to determine the most efficacious dose of EIDD2801 per virus. For SARS-CoV, in cohorts of equivalent numbers of male and female 20-29 week old SPF C57BL/6J (Stock 000664 Jackson Labs) mice ( $n=10 /$ dose group), we administered vehicle (10\% PEG, $2.5 \%$ Cremophor RH40 in water) or 50,150 or $500 \mathrm{mg} / \mathrm{kg}$ EIDD-2801 by oral gavage 2 hours prior to intranasal infection with $1 \mathrm{E}+04$ PFU mouse-adapted SARS-CoV strain MA15 in 50 $\mu$ l. Mice were anaesthetized with a mixture of ketamine/xylazine prior to intranasal infection. Vehicle or drug was administered every $12 \mathrm{hr}$ for the remainder of the study. Body weight and pulmonary function by whole body plethysmography were measured daily. On $5 \mathrm{dpi}$, animals were sacrificed by isoflurane overdose, lungs were scored for lung hemorrhage, and the inferior right lobe was frozen at $-80^{\circ} \mathrm{C}$ for viral titration via plaque assay. Briefly, 500,000 Vero E6 cells/well were seeded in 6-well plates. The following day, medium was removed and serial dilutions of clarified lung homogenate were added per plate $\left(10^{-1}\right.$ to $10^{-6}$ dilutions) and incubated at $37^{\circ} \mathrm{C}$ for $1 \mathrm{hr}$ after which wells were overlaid with 1X DMEM, 5\% Fetal Clone 2 serum, 1X antibiotic/antimycotic, $0.8 \%$ agarose. Two days after, plaques were enumerated to generate a plaque $/ \mathrm{ml}$ value. Lung hemorrhage is a gross pathological phenotype readily observed by the naked eye driven by the degree of virus replication where the coloration of the lung changes from pink to dark red $(62,63)$. The large left lobe was placed in $10 \%$ buffered formalin and stored at $4{ }^{\circ} \mathrm{C}$ for 1-3 weeks until histological sectioning and analysis. For MERS-CoV, the prophylactic dose escalation studies we performed similarly as done for SARS-CoV with our recently developed a mouse model for MERS-CoV, which has a humanized DPP4 receptor (hDPP4) (28). We performed all in vivo studies with EIDD-2801 in equivalent numbers of 10-14 week old female and male C57BL/6J hDPP4 mice. Second, we intranasally infected mice with 5E+04 PFU mouse-adapted MERS-CoV strain M35C4 in $50 \mu l$. Third, to titer lungs by plaque assay, Vero CCL81 cells were used and plaques were enumerated $3 \mathrm{dpi}$.

To determine the time at which therapeutic administration of EIDD-2801 would fail to improve outcomes with SARS-CoV or MERS-CoV infection, we performed therapeutic efficacy studies in mice where we initiated treatment 2 hours prior to infection or 12,24 or 48 hours after infection. As 500 $\mathrm{mg} / \mathrm{kg}$ provided the most complete protection from disease in prophylactic SARS-CoV studies, this dose was used for both therapeutic efficacy studies. Vehicle or EIDD-2801 was given via oral gavage twice daily following initiation of treatment. For both SARS-CoV and MERS-CoV, the infectious dose for the therapeutic studies and the mouse strains were the same as that used in the prophylactic studies. The numbers of mice per group for the SARS-CoV studies were as follows: Vehicle $(\mathrm{n}=10),-2$ hours $(\mathrm{n}=10),+12$ hours $(\mathrm{n}=10),+24$ hours $(\mathrm{n}=$ $10),+48$ hours $(n=10)$. The numbers of mice per group for the MERS-CoV therapeutic studies were as follows: Vehicle $(\mathrm{n}=9),-2$ hours $(\mathrm{n}=9),+12$ hours $(\mathrm{n}=9),+24$ hours $(\mathrm{n}=7)$, +48 hours $(\mathrm{n}=10)$. As described above, each day mouse body weight and pulmonary function were quantitated. On 5 dpi for SARS-CoV and 6 dpi for MERS-CoV, animals were humanely sacrificed and tissues were harvested and analyzed as described above. In addition, for the MERS-CoV study, lung tissue was harvested and stored in RNAlater (Thermo Fisher) at $-80^{\circ} \mathrm{C}$ and then thawed, homogenized in Trizol reagent (Invitrogen) and total RNA was isolated using a Direct-zol RNA MiniPrep kit (Zymo Research). This total RNA was then used for Primer ID and qRT-PCR.

\section{Whole body plethysmography}

Pulmonary function was monitored once daily via wholebody plethysmography (Buxco Respiratory Solutions, DSI Inc.). Mice intended for this analysis were randomly chosen prior to the initiation of the study. Briefly, after a 30-min acclimation time in the plethysmograph, data for 11 parameters was recorded every $2 \mathrm{~s}$ for $5 \mathrm{~min}$.

\section{Acute lung injury histological assessment tools}

Two different and complementary quantitative histologic tools were used to determine if antiviral treatments 
diminished the histopathologic features associated with lung injury. Both analyses and scoring were performed by a Board Certified Veterinary Pathologist who was blinded to the treatment groups.

American Thoracic Society lung injury scoring tool. In order to help quantitate histological features of ALI observed in mouse models and increase their translation to the human condition, we used the ATS scoring tool (63). In a blinded manner, we chose three random diseased fields of lung tissue at high power $(60 \times)$, which were scored for the following: (A) neutrophils in the alveolar space (none $=0,1-5$ cells $=1$, $>5$ cells $=2$ ), $(\mathrm{B})$ neutrophils in the interstitial space/ septae (none $=0,1-5$ cells $=1,>5$ cells $=2$ ), $(\mathrm{C})$ hyaline membranes (none $=0$, one membrane $=1,>1$ membrane $=2$ ), (D) Proteinaceous debris in air spaces (none $=0$, one instance $=1$, > 1 instance $=2)$, (E) alveolar septal thickening $(<2 \times$ mock thickness $=0,2-4 \times$ mock thickness $=1,>4 \times$ mock thickness $=2$ ). To obtain a lung injury score per field, the scores for A$\mathrm{E}$ were then put into the following formula, which contains multipliers that assign varying levels of importance for each phenotype of the disease state.: score $=[(20 \mathrm{x} \mathrm{A})+(14 \times \mathrm{B})+$ $(7 \times \mathrm{C})+(7 \times \mathrm{D})+(2 \times \mathrm{E})] / 100$. The scores for the three fields per mouse were averaged to obtain a final score ranging from 0 to and including 1.

Diffuse Alveolar Damage (DAD) tool. The second histological tool to quantitate lung injury was reported by Schmidt $e t$ al.(64). DAD is the pathological hallmark of ALI $(63,64)$. Three random diseased fields of lung tissue were scored at high power $(60 \times)$ for the following in a blinded manner: $1=$ absence of cellular sloughing and necrosis, $2=$ Uncommon solitary cell sloughing and necrosis (1-2 foci/field), $3=$ multifocal ( $3+$ foci) cellular sloughing and necrosis with uncommon septal wall hyalinization, or $4=$ multifocal $(>75 \%$ of field) cellular sloughing and necrosis with common and/or prominent hyaline membranes. The scores for the three fields per mouse were averaged to get a final DAD score per mouse.

nsp12 phylogenetic analysis and conservation modeling Coronavirus RdRp (nsp12) protein sequence alignments and phylogenetic trees were generated using Geneious Tree Builder in Geneious Prime (version 2020.0.5) and visualized using Evolview (https://www.evolgenius.info/evolview/). Protein similarity scores were calculated using Blosom62 matrix. The accession numbers used were: PDCoV (KR265858), AIBV (NC_001451), HCoV-229E (JX503060), PEDV (NC_003436), MHV (AY700211), HCoV-HKU1 (DQ415904), HCoV-NL63 (JX504050), HCOV-OC43 (AY903460), HKU5-1 (NC_009020), MERS-CoV (JX869059), HKU9-4 (EF065516), 2019-nCoV (MN996528), HKU3-1 (DQ022305), SHC014 (KC881005), WIV1 (KF367457), SARS-CoV (AY278741). Amino acid conservation scores of coronavirus RdRp were generated using ConSurf Server (https://consurf.tau.ac.il/) using the protein alignment described above and visualized on the
SARS-CoV RdRp structure (PDB: 6NUR) in PyMol (version 1.8.6.0)(20, 65).

\section{Statistical analysis}

All statistical data analyses were performed in Graphpad Prism 8. Statistical significance for each endpoint was determined with specific statistical tests. In general, for metrics with multiple treatment groups with longitudinal data (e.g., mouse weight loss or pulmonary function over time), twoway ANOVA was performed with the suggested multiple comparison test as advised by Prism. For comparative data with for a single timepoint (e.g., lung titer) Kruskal-Wallis or oneway ANOVA was performed with the suggested multiple comparison test. For each test, a p-value $<0.05$ was considered significant. Specific tests are noted in each figure legend.

\section{SUPPLEMENTARY MATERIALS}

stm.sciencemag.org/cgi/content/full/scitranslmed.abb5883/DC1

Supplementary Figure 1. Assessment of cytotoxicity of NHC in primary human epithelial cell cultures by qRT-PCR.

Supplementary Figure 2. High conservation of RdRp functional domains for SARSCoV-2.

Supplementary Figure 3. Prophylactic EIDD-2801 reduces SARS-CoV replication and pathogenesis.

Supplementary Figure 4. Prophylactic EIDD-2801 reduces MERS-CoV replication and pathogenesis.

Supplementary Table 1. Real-time PCR primer/probe sets for indicators of cellular apoptosis/toxicity.

Supplementary Table 2. Primers used for MiSeq library prep and sequencing.

Data file S1. Primary data.

\section{REFERENCES AND NOTES}

1. World Health Organization, Middle East respiratory syndrome coronavirus (MERSCoV); www.who.int/emergencies/mers-cov/en/.

2. E. de Wit, N. van Doremalen, D. Falzarano, V. J. Munster, SARS and MERS: Recent insights into emerging coronaviruses. Nat. Rev. Microbiol. 14, 523-534 (2016). doi:10.1038/nrmicro.2016.81 Medline

3. D. Wang, B. Hu, C. Hu, F. Zhu, X. Liu, J. Zhang, B. Wang, H. Xiang, Z. Cheng, Y. Xiong, Y. Zhao, Y. Li, X. Wang, Z. Peng, Clinical Characteristics of 138 Hospitalized Patients With 2019 Novel Coronavirus-Infected Pneumonia in Wuhan, China. JAMA 323, 1061 (2020). doi:10.1001/jama.2020.1585 Medline

4. S. J. Anthony, K. Gilardi, V. D. Menachery, T. Goldstein, B. Ssebide, R. Mbabazi, I. Navarrete-Macias, E. Liang, H. Wells, A. Hicks, A. Petrosov, D. K. Byarugaba, K. Debbink, K. H. Dinnon, T. Scobey, S. H. Randell, B. L. Yount, M. Cranfield, C. K. Johnson, R. S. Baric, W. I. Lipkin, J. A. Mazet, Further Evidence for Bats as the Evolutionary Source of Middle East Respiratory Syndrome Coronavirus. mBio 8 , e00373-17 (2017). doi:10.1128/mBio.00373-17 Medline

5. B. Hu, X. Ge, L. F. Wang, Z. Shi, Bat origin of human coronaviruses. Virol. J. 12, 221 (2015). doi:10.1186/s12985-015-0422-1 Medline

6. J. Huynh, S. Li, B. Yount, A. Smith, L. Sturges, J. C. Olsen, J. Nagel, J. B. Johnson, S. Agnihothram, J. E. Gates, M. B. Frieman, R. S. Baric, E. F. Donaldson, Evidence supporting a zoonotic origin of human coronavirus strain NL63. J. Virol. 86, 12816-12825 (2012). doi:10.1128/JVI.00906-12 Medline

7. A. M. Zaki, S. van Boheemen, T. M. Bestebroer, A. D. Osterhaus, R. A. Fouchier, Isolation of a novel coronavirus from a man with pneumonia in Saudi Arabia. N. Engl. J. Med. 367, 1814-1820 (2012). doi:10.1056/NEJMoa1211721 Medline

8. L. Y. Hsu, C. C. Lee, J. A. Green, B. Ang, N. I. Paton, L. Lee, J. S. Villacian, P. L. Lim, A. Earnest, Y. S. Leo, Severe acute respiratory syndrome (SARS) in Singapore: Clinical features of index patient and initial contacts. Emerg. Infect. Dis. 9, 713717 (2003). doi:10.3201/eid0906.030264 Medline

9. P. Zhou, H. Fan, T. Lan, X. L. Yang, W. F. Shi, W. Zhang, Y. Zhu, Y. W. Zhang, Q. M. Xie, S. Mani, X. S. Zheng, B. Li, J. M. Li, H. Guo, G. Q. Pei, X. P. An, J. W. Chen, L. 
Zhou, K. J. Mai, Z. X. Wu, D. Li, D. E. Anderson, L. B. Zhang, S. Y. Li, Z. Q. Mi, T. T. He, F. Cong, P. J. Guo, R. Huang, Y. Luo, X. L. Liu, J. Chen, Y. Huang, Q. Sun, X. L. Zhang, Y. Y. Wang, S. Z. Xing, Y. S. Chen, Y. Sun, J. Li, P. Daszak, L. F. Wang, Z. L. Shi, Y. G. Tong, J. Y. Ma, Fatal swine acute diarrhoea syndrome caused by an HKU2-related coronavirus of bat origin. Nature 556, 255-258 (2018). doi:10.1038/s41586-018-0010-9 Medline

10. P. C. Woo, S. K. Lau, K. S. Li, R. W. Poon, B. H. Wong, H. W. Tsoi, B. C. Yip, Y. Huang, K. H. Chan, K. Y. Yuen, Molecular diversity of coronaviruses in bats. Virology 351 , 180-187 (2006). doi:10.1016/i.virol.2006.02.041 Medline

11. V. D. Menachery, B. L. Yount Jr., K. Debbink, S. Agnihothram, L. E. Gralinski, J. A. Plante, R. L. Graham, T. Scobey, X. Y. Ge, E. F. Donaldson, S. H. Randell, A. Lanzavecchia, W. A. Marasco, Z. L. Shi, R. S. Baric, A SARS-like cluster of circulating bat coronaviruses shows potential for human emergence. Nat. Med. 21, 1508-1513 (2015). doi:10.1038/nm.3985 Medline

12. V. D. Menachery, B. L. Yount Jr., A. C. Sims, K. Debbink, S. S. Agnihothram, L. E. Gralinski, R. L. Graham, T. Scobey, J. A. Plante, S. R. Royal, J. Swanstrom, T. P. Sheahan, R. J. Pickles, D. Corti, S. H. Randell, A. Lanzavecchia, W. A. Marasco, R. S. Baric, SARS-like WIV1-CoV poised for human emergence. Proc. Natl. Acad. Sci. U.S.A. 113, 3048-3053 (2016). doi:10.1073/pnas.1517719113 Medline

13. O. Reynard, X. N. Nguyen, N. Alazard-Dany, V. Barateau, A. Cimarelli, V. E. Volchkov, Identification of a New Ribonucleoside Inhibitor of Ebola Virus Replication. Viruses 7, 6233-6240 (2015). doi:10.3390/v7122934 Medline

14. N. Urakova, V. Kuznetsova, D. K. Crossman, A. Sokratian, D. B. Guthrie, A. A. Kolykhalov, M. A. Lockwood, M. G. Natchus, M. R. Crowley, G. R. Painter, E. I. Frolova, I. Frolov, $\beta$-d-N4-Hydroxycytidine Is a Potent Anti-alphavirus Compound That Induces a High Level of Mutations in the Viral Genome. J. Virol. 92, ... (2018). Medline

15. M. Toots, J. J. Yoon, R. M. Cox, M. Hart, Z. M. Sticher, N. Makhsous, R. Plesker, A. H. Barrena, P. G. Reddy, D. G. Mitchell, R. C. Shean, G. R. Bluemling, A. A. Kolykhalov, A. L. Greninger, M. G. Natchus, G. R. Painter, R. K. Plemper, Characterization of orally efficacious influenza drug with high resistance barrier in ferrets and human airway epithelia. Sci. Transl. Med. 11, eaax5866 (2019). doi:10.1126/scitranslmed.aax5866 Medline

16. M. L. Agostini, A. J. Pruijssers, J. D. Chappell, J. Gribble, X. Lu, E. L. Andres, G. R. Bluemling, M. A. Lockwood, T. P. Sheahan, A. C. Sims, M. G. Natchus, M. Saindane, A. A. Kolykhalov, G. R. Painter, R. S. Baric, M. R. Denison, Small-Molecule Antiviral $\beta-d-N^{4}$-Hydroxycytidine Inhibits a Proofreading-Intact Coronavirus with a High Genetic Barrier to Resistance. J. Virol. 93, e01348-19 (2019). doi:10.1128/JVI.01348-19 Medline

17. P. C. Jordan, C. Liu, P. Raynaud, M. K. Lo, C. F. Spiropoulou, J. A. Symons, L. Beigelman, J. Deval, Initiation, extension, and termination of RNA synthesis by a paramyxovirus polymerase. PLOS Pathog. 14, el006889 (2018). doi:10.1371/journal.ppat.1006889 Medline

18. T. P. Sheahan, A. C. Sims, S. R. Leist, A. Schäfer, J. Won, A. J. Brown, S. A. Montgomery, A. Hogg, D. Babusis, M. O. Clarke, J. E. Spahn, L. Bauer, S. Sellers, D. Porter, J. Y. Feng, T. Cihlar, R. Jordan, M. R. Denison, R. S. Baric, Comparative therapeutic efficacy of remdesivir and combination lopinavir, ritonavir, and interferon beta against MERS-CoV. Nat. Commun. 11, 222 (2020). doi:10.1038/s41467-019-13940-6 Medline

19. T. P. Sheahan, A. C. Sims, R. L. Graham, V. D. Menachery, L. E. Gralinski, J. B. Case, S. R. Leist, K. Pyrc, J. Y. Feng, I. Trantcheva, R. Bannister, Y. Park, D. Babusis, M. O. Clarke, R. L. Mackman, J. E. Spahn, C. A. Palmiotti, D. Siegel, A. S. Ray, T. Cihlar, R. Jordan, M. R. Denison, R. S. Baric, Broad-spectrum antiviral GS-5734 inhibits both epidemic and zoonotic coronaviruses. Sci. Transl. Med. 9, eaal3653 (2017). doi:10.1126/scitranslmed.aal3653 Medline

20. R. N. Kirchdoerfer, A. B. Ward, Structure of the SARS-CoV nsp12 polymerase bound to nsp7 and nsp8 co-factors. Nat. Commun. 10, 2342 (2019). doi:10.1038/s41467-019-10280-3 Medline

21. M. L. Agostini, E. L. Andres, A. C. Sims, R. L. Graham, T. P. Sheahan, X. Lu, E. C. Smith, J. B. Case, J. Y. Feng, R. Jordan, A. S. Ray, T. Cihlar, D. Siegel, R. L. Mackman, M. O. Clarke, R. S. Baric, M. R. Denison, Coronavirus Susceptibility to the Antiviral Remdesivir (GS-5734) Is Mediated by the Viral Polymerase and the Proofreading Exoribonuclease. mBio 9, e00221-18 (2018). doi:10.1128/mBio.00221-18 Medline

22. M. M. Becker, R. L. Graham, E. F. Donaldson, B. Rockx, A. C. Sims, T. Sheahan, R.
J. Pickles, D. Corti, R. E. Johnston, R. S. Baric, M. R. Denison, Synthetic recombinant bat SARS-like coronavirus is infectious in cultured cells and in mice. Proc. Natl. Acad. Sci. U.S.A. 105, 19944-19949 (2008). doi:10.1073/pnas.0808116105 Medline

23. S. Agnihothram, B. L. Yount Jr., E. F. Donaldson, J. Huynh, V. D. Menachery, L. E. Gralinski, R. L. Graham, M. M. Becker, S. Tomar, T. D. Scobey, H. L. Osswald, A. Whitmore, R. Gopal, A. K. Ghosh, A. Mesecar, M. Zambon, M. Heise, M. R. Denison, R. S. Baric, A mouse model for Betacoronavirus subgroup $2 \mathrm{c}$ using a bat coronavirus strain HKU5 variant. mBio 5, e00047-e14 (2014). doi:10.1128/mBio.00047-14 Medline

24. J. J. Yoon, M. Toots, S. Lee, M. E. Lee, B. Ludeke, J. M. Luczo, K. Ganti, R. M. Cox, Z. M. Sticher, V. Edpuganti, D. G. Mitchell, M. A. Lockwood, A. A. Kolykhalov, A. L. Greninger, M. L. Moore, G. R. Painter, A. C. Lowen, S. M. Tompkins, R. Fearns, M. G. Natchus, R. K. Plemper, Orally Efficacious Broad-Spectrum Ribonucleoside Analog Inhibitor of Influenza and Respiratory Syncytial Viruses. Antimicrob. Agents Chemother. 62, e00766-18 (2018). doi:10.1128/AAC.00766-18 Medline

25. S. Zhou, C. Jones, P. Mieczkowski, R. Swanstrom, Primer ID Validates Template Sampling Depth and Greatly Reduces the Error Rate of Next-Generation Sequencing of HIV-1 Genomic RNA Populations. J. Virol. 89, 8540-8555 (2015). doi:10.1128/JVI.00522-15 Medline

26. E. P. Tchesnokov, J. Y. Feng, D. P. Porter, M. Götte, Mechanism of Inhibition of Ebola Virus RNA-Dependent RNA Polymerase by Remdesivir. Viruses 11, 326 (2019). doi:10.3390/v11040326 Medline

27. V. D. Menachery, L. E. Gralinski, R. S. Baric, M. T. Ferris, New Metrics for Evaluating Viral Respiratory Pathogenesis. PLOS ONE 10, e0131451 (2015). doi:10.1371/journal.pone.0131451 Medline

28. A. S. Cockrell, B. L. Yount, T. Scobey, K. Jensen, M. Douglas, A. Beall, X. C. Tang, W. A. Marasco, M. T. Heise, R. S. Baric, A mouse model for MERS coronavirusinduced acute respiratory distress syndrome. Nat. Microbiol. 2, 16226 (2016). doi:10.1038/nmicrobiol.2016.226 Medline

29. H. D. Marston, G. K. Folkers, D. M. Morens, A. S. Fauci, Emerging viral diseases: Confronting threats with new technologies. Sci. Transl. Med. 6, 253ps10 (2014). doi:10.1126/scitranslmed.3009872 Medline

30. C. I. Paules, H. D. Marston, A. S. Fauci, Coronavirus Infections-More Than Just the Common Cold. JAMA 323, 707 (2020). doi:10.1001/jama.2020.0757 Medline

31. A. J. Brown, J. J. Won, R. L. Graham, K. H. Dinnon 3rd, A. C. Sims, J. Y. Feng, T. Cihlar, M. R. Denison, R. S. Baric, T. P. Sheahan, Broad spectrum antiviral remdesivir inhibits human endemic and zoonotic deltacoronaviruses with a highly divergent RNA dependent RNA polymerase. Antiviral Res. 169, 104541 (2019). doi:10.1016/i.antiviral.2019.104541 Medline

32. A. Zumla, J. F. Chan, E. I. Azhar, D. S. Hui, K. Y. Yuen, Coronaviruses - drug discovery and therapeutic options. Nat. Rev. Drug Discov. 15, 327-347 (2016). doi:10.1038/nrd.2015.37 Medline

33. A. Cortegiani, G. Ingoglia, M. Ippolito, A. Giarratano, S. Einav, A systematic review on the efficacy and safety of chloroquine for the treatment of COVID-19. J. Crit. Care S0883-9441(20)30390-7 (2020). doi:10.1016/j.jcrc.2020.03.005 Medline

34. F. X. Lescure, L. Bouadma, D. Nguyen, M. Parisey, P. H. Wicky, S. Behillil, A. Gaymard, M. Bouscambert-Duchamp, F. Donati, Q. Le Hingrat, V. Enouf, N. Houhou-Fidouh, M. Valette, A. Mailles, J. C. Lucet, F. Mentre, X. Duval, D. Descamps, D. Malvy, J. F. Timsit, B. Lina, S. van-der-Werf, Y. Yazdanpanah, Clinical and virological data of the first cases of COVID-19 in Europe: A case series. Lancet Infect. Dis. S1473-3099(20)30200-0 (2020). doi:10.1016/S14733099(20)30200-0 Medline

35. B. Cao, Y. Wang, D. Wen, W. Liu, J. Wang, G. Fan, L. Ruan, B. Song, Y. Cai, M. Wei, X. Li, J. Xia, N. Chen, J. Xiang, T. Yu, T. Bai, X. Xie, L. Zhang, C. Li, Y. Yuan, H. Chen, H. Li, H. Huang, S. Tu, F. Gong, Y. Liu, Y. Wei, C. Dong, F. Zhou, X. Gu, J. Xu, Z. Liu, Y. Zhang, H. Li, L. Shang, K. Wang, K. Li, X. Zhou, X. Dong, Z. Qu, S. Lu, X. Hu, S. Ruan, S. Luo, J. Wu, L. Peng, F. Cheng, L. Pan, J. Zou, C. Jia, J. Wang, X. Liu, S. Wang, X. Wu, Q. Ge, J. He, H. Zhan, F. Qiu, L. Guo, C. Huang, T. Jaki, F. G. Hayden, P. W. Horby, D. Zhang, C. Wang, A Trial of Lopinavir-Ritonavir in Adults Hospitalized with Severe Covid-19. N. Engl. J. Med. NEJMoa2001282 (2020). doi:10.1056/NEJMoa2001282 Medline

36. M. Ehteshami, S. Tao, K. Zandi, H. M. Hsiao, Y. Jiang, E. Hammond, F. Amblard, O. 0 . Russell, A. Merits, R. F. Schinazi, Characterization of $\beta-d-N^{4}-H y d r o x y c y t i d i n e$ as a Novel Inhibitor of Chikungunya Virus. Antimicrob. Agents Chemother. 61, 
e02395-16 (2017). doi:10.1128/AAC.02395-16 Medline

37. T. K. Warren, R. Jordan, M. K. Lo, A. S. Ray, R. L. Mackman, V. Soloveva, D. Siegel, M. Perron, R. Bannister, H. C. Hui, N. Larson, R. Strickley, J. Wells, K. S. Stuthman, S. A. Van Tongeren, N. L. Garza, G. Donnelly, A. C. Shurtleff, C. J. Retterer, D. Gharaibeh, R. Zamani, T. Kenny, B. P. Eaton, E. Grimes, L. S. Welch, L. Gomba, C. L. Wilhelmsen, D. K. Nichols, J. E. Nuss, E. R. Nagle, J. R. Kugelman, G. Palacios, E. Doerffler, S. Neville, E. Carra, M. O. Clarke, L. Zhang, W. Lew, B. Ross, Q. Wang, K. Chun, L. Wolfe, D. Babusis, Y. Park, K. M. Stray, I. Trancheva, J. Y. Feng, O. Barauskas, Y. Xu, P. Wong, M. R. Braun, M. Flint, L. K. McMullan, S. S. Chen, R. Fearns, S. Swaminathan, D. L. Mayers, C. F. Spiropoulou, W. A. Lee, S. T. Nichol, T. Cihlar, S. Bavari, Therapeutic efficacy of the small molecule GS-5734 against Ebola virus in rhesus monkeys. Nature 531, 381-385 (2016). doi:10.1038/nature17180 Medline

38. M. K. Lo, R. Jordan, A. Arvey, J. Sudhamsu, P. Shrivastava-Ranjan, A. L. Hotard, M. Flint, L. K. McMullan, D. Siegel, M. O. Clarke, R. L. Mackman, H. C. Hui, M. Perron, A. S. Ray, T. Cihlar, S. T. Nichol, C. F. Spiropoulou, GS-5734 and its parent nucleoside analog inhibit Filo-, Pneumo-, and Paramyxoviruses. Sci. Rep. 7, 43395 (2017). doi:10.1038/srep43395 Medline

39. M. D. Oh, W. B. Park, P. G. Choe, S. J. Choi, J. I. Kim, J. Chae, S. S. Park, E. C. Kim, H. S. Oh, E. J. Kim, E. Y. Nam, S. H. Na, D. K. Kim, S. M. Lee, K. H. Song, J. H. Bang, E. S. Kim, H. B. Kim, S. W. Park, N. J. Kim, Viral Load Kinetics of MERS Coronavirus Infection. N. Engl. J. Med. 375, 1303-1305 (2016). doi:10.1056/NEJMc1511695 Medline

40. J. S. Peiris, C. M. Chu, V. C. Cheng, K. S. Chan, I. F. Hung, L. L. Poon, K. I. Law, B. S. Tang, T. Y. Hon, C. S. Chan, K. H. Chan, J. S. Ng, B. J. Zheng, W. L. Ng, R. W. Lai, Y. Guan, K. Y. Yuen; HKU/UCH SARS Study Group, Clinical progression and viral load in a community outbreak of coronavirus-associated SARS pneumonia: A prospective study. Lancet 361, 1767-1772 (2003). doi:10.1016/S01406736(03)13412-5 Medline

41. R. Wölfel, V. M. Corman, W. Guggemos, M. Seilmaier, S. Zange, M. A. Müller, D. Niemeyer, T. C. Jones, P. Vollmar, C. Rothe, M. Hoelscher, T. Bleicker, S. Brünink, J. Schneider, R. Ehmann, K. Zwirglmaier, C. Drosten, C. Wendtner, Virological assessment of hospitalized patients with COVID-2019. Nature (2020). doi:10.1038/s41586-020-2196-x Medline

42. H. Yu, Z. Feng, T. M. Uyeki, Q. Liao, L. Zhou, L. Feng, M. Ye, N. Xiang, Y. Huai, Y. Yuan, H. Jiang, Y. Zheng, P. Gargiullo, Z. Peng, Y. Feng, J. Zheng, C. Xu, Y. Zhang, Y. Shu, Z. Gao, W. Yang, Y. Wang, Risk factors for severe illness with 2009 pandemic influenza A (H1N1) virus infection in China. Clin. Infect. Dis. 52, 457-465 (2011). doi:10.1093/cid/ciq144 Medline

43. Y. Wan, J. Shang, R. Graham, R. S. Baric, F. Li, Receptor recognition by novel coronavirus from Wuhan: An analysis based on decade-long structural studies of SARS coronavirus. J. Virol. 94, e00127-20 (2020). doi:10.1128/JVI.00127-20 Medline

44. P. Zhou, X.-L. Yang, X.-G. Wang, B. Hu, L. Zhang, W. Zhang, H.-R. Si, Y. Zhu, B. Li, C.-L. Huang, H.-D. Chen, J. Chen, Y. Luo, H. Guo, R.-D. Jiang, M.-Q. Liu, Y. Chen, X.-R. Shen, X. Wang, X.-S. Zheng, K. Zhao, Q.-J. Chen, F. Deng, L.-L. Liu, B. Yan, F.X. Zhan, Y.-Y. Wang, G. Xiao, Z.-L. Shi, Discovery of a novel coronavirus associated with the recent pneumonia outbreak in humans and its potential bat origin. bioRxiv, 2020.2001.2022.914952 (2020).

45. T. Sheahan, A. Whitmore, K. Long, M. Ferris, B. Rockx, W. Funkhouser, E. Donaldson, L. Gralinski, M. Collier, M. Heise, N. Davis, R. Johnston, R. S. Baric, Successful vaccination strategies that protect aged mice from lethal challenge from influenza virus and heterologous severe acute respiratory syndrome coronavirus. J. Virol. 85, 217-230 (2011). doi:10.1128/JVI.01805-10 Medline

46. E. de Wit, A. L. Rasmussen, D. Falzarano, T. Bushmaker, F. Feldmann, D. L. Brining, E. R. Fischer, C. Martellaro, A. Okumura, J. Chang, D. Scott, A. G. Benecke, M. G. Katze, H. Feldmann, V. J. Munster, Middle East respiratory syndrome coronavirus (MERS-CoV) causes transient lower respiratory tract infection in rhesus macaques. Proc. Natl. Acad. Sci. U.S.A. 110, 16598-16603 (2013). doi:10.1073/pnas.1310744110 Medline

47. J. McAuliffe, L. Vogel, A. Roberts, G. Fahle, S. Fischer, W.-J. Shieh, E. Butler, S. Zaki, M. St Claire, B. Murphy, K. Subbarao, Replication of SARS coronavirus administered into the respiratory tract of African Green, rhesus and cynomolgus monkeys. Virology 330, 8-15 (2004). doi:10.1016/j.virol.2004.09.030 Medline

48. V. J. Munster, F. Feldmann, B. N. Williamson, N. van Doremalen, L. Pérez-Pérez, J.
Schulz, K. Meade-White, A. Okumura, J. Callison, B. Brumbaugh, V. A. Avanzato, R. Rosenke, P. W. Hanley, G. Saturday, D. Scott, E. R. Fischer, E. de Wit, Respiratory disease and virus shedding in rhesus macaques inoculated with SARS-CoV-2. bioRxiv, 2020.2003.2021.001628 (2020).

49. B. Rockx, T. Kuiken, S. Herfst, T. Bestebroer, M. M. Lamers, D. de Meulder, G. van Amerongen, J. van den Brand, N. M. A. Okba, D. Schipper, P. van Run, L. Leijten, E. Verschoor, B. Verstrepen, J. Langermans, C. Drosten, M. F. van Vlissingen, R. Fouchier, R. de Swart, M. Koopmans, B. L. Haagmans, Comparative Pathogenesis Of COVID-19, MERS And SARS In A Non-Human Primate Model. bioRxiv, 2020.2003.2017.995639 (2020).

50. E. C. Smith, H. Blanc, M. C. Surdel, M. Vignuzzi, M. R. Denison, Coronaviruses lacking exoribonuclease activity are susceptible to lethal mutagenesis: Evidence for proofreading and potential therapeutics. PLOS Pathog. 9, e1003565 (2013). doi:10.1371/journal.ppat.1003565 Medline

51. T. Suzuki, K. Moriyama, C. Otsuka, D. Loakes, K. Negishi, Template properties of mutagenic cytosine analogues in reverse transcription. Nucleic Acids Res. 34 , 6438-6449 (2006). doi:10.1093/nar/gk1761 Medline

52. M. L. Fulcher, S. H. Randell, Human nasal and tracheo-bronchial respiratory epithelial cell culture. Methods Mol. Biol. 945, 109-121 (2013). doi:10.1007/9781-62703-125-7 8 Medline

53. A. C. Sims, R. S. Baric, B. Yount, S. E. Burkett, P. L. Collins, R. J. Pickles, Severe acute respiratory syndrome coronavirus infection of human ciliated airway epithelia: Role of ciliated cells in viral spread in the conducting airways of the lungs. J. Virol. 79, 15511-15524 (2005). doi:10.1128/JVI.79.24.15511-15524.2005 Medline

54. J. Harcourt, A. Tamin, X. Lu, S. Kamili, S. K. Sakthivel, J. Murray, K. Queen, Y. Tao, C. R. Paden, J. Zhang, Y. Li, A. Uehara, H. Wang, C. Goldsmith, H. A. Bullock, L. Wang, B. Whitaker, B. Lynch, R. Gautam, C. Schindewolf, K. G. Lokugamage, D. Scharton, J. A. Plante, D. Mirchandani, S. G. Widen, K. Narayanan, S. Makino, T. G. Ksiazek, K. S. Plante, S. C. Weaver, S. Lindstrom, S. Tong, V. D. Menachery, N. J. Thornburg, Severe Acute Respiratory Syndrome Coronavirus 2 from Patient with 2019 Novel Coronavirus Disease, United States. Emerg. Infect. Dis. 26, ..• (2020). doi:10.3201/eid2606.200516 Medline

55. T. Scobey, B. L. Yount, A. C. Sims, E. F. Donaldson, S. S. Agnihothram, V. D. Menachery, R. L. Graham, J. Swanstrom, P. F. Bove, J. D. Kim, S. Grego, S. H. Randell, R. S. Baric, Reverse genetics with a full-length infectious cDNA of the Middle East respiratory syndrome coronavirus. Proc. Natl. Acad. Sci. U.S.A. 110, 16157-16162 (2013). doi:10.1073/pnas.1311542110 Medline

56. M. G. Douglas, J. F. Kocher, T. Scobey, R. S. Baric, A. S. Cockrell, Adaptive evolution influences the infectious dose of MERS-CoV necessary to achieve severe respiratory disease. Virology 517, 98-107 (2018). doi:10.1016/j,virol.2017.12.006 Medline

57. A. Roberts, D. Deming, C. D. Paddock, A. Cheng, B. Yount, L. Vogel, B. D. Herman, T. Sheahan, M. Heise, G. L. Genrich, S. R. Zaki, R. Baric, K. Subbarao, A mouseadapted SARS-coronavirus causes disease and mortality in BALB/c mice. PLOS Pathog. 3, e5 (2007). doi:10.1371/journal.ppat.0030005 Medline

58. B. Yount, M. R. Denison, S. R. Weiss, R. S. Baric, Systematic assembly of a fulllength infectious CDNA of mouse hepatitis virus strain A59. J. Virol. 76, 1106511078 (2002). doi:10.1128/JVI.76.21.11065-11078.2002 Medline

59. M. L. Fulcher, S. Gabriel, K. A. Burns, J. R. Yankaskas, S. H. Randell, Welldifferentiated human airway epithelial cell cultures. Methods Mol. Med. 107, 183206 (2005). Medline

60. F. Almazán, M. L. DeDiego, I. Sola, S. Zuñiga, J. L. Nieto-Torres, S. MarquezJurado, G. Andrés, L. Enjuanes, Engineering a replication-competent, propagation-defective Middle East respiratory syndrome coronavirus as a vaccine candidate. mBio 4, e00650-e13 (2013). doi:10.1128/mBio.00650-13 Medline

61. C. B. Jabara, C. D. Jones, J. Roach, J. A. Anderson, R. Swanstrom, Accurate sampling and deep sequencing of the HIV-1 protease gene using a Primer ID. Proc. Natl. Acad. Sci. U.S.A. 108, 20166-20171 (2011). doi:10.1073/pnas.1110064108 Medline

62. M. Fukushi, T. Ito, T. Oka, T. Kitazawa, T. Miyoshi-Akiyama, T. Kirikae, M. Yamashita, K. Kudo, Serial histopathological examination of the lungs of mice infected with influenza A virus PR8 strain. PLOS ONE 6, e21207 (2011). doi:10.1371/journal.pone.0021207 Medline

63. G. Matute-Bello, G. Downey, B. B. Moore, S. D. Groshong, M. A. Matthay, A. S. 
Slutsky, W. M. Kuebler; Acute Lung Injury in Animals Study Group, An official American Thoracic Society workshop report: Features and measurements of experimental acute lung injury in animals. Am. J. Respir. Cell Mol. Biol. 44, 725738 (2011). doi:10.1165/rcmb.2009-0210ST Medline

64. M. E. Schmidt, C. J. Knudson, S. M. Hartwig, L. L. Pewe, D. K. Meyerholz, R. A. Langlois, J. T. Harty, S. M. Varga, Memory CD8 T cells mediate severe immunopathology following respiratory syncytial virus infection. PLOS Pathog. 14, e1006810 (2018). doi:10.1371/journal.ppat.1006810 Medline

65. H. Ashkenazy, S. Abadi, E. Martz, O. Chay, I. Mayrose, T. Pupko, N. Ben-Tal, ConSurf 2016: An improved methodology to estimate and visualize evolutionary conservation in macromolecules. Nucleic Acids Res. 44 (W1), W344-W350 (2016). doi:10.1093/nar/gkw408 Medline

Acknowledgments: Funding: We would like to acknowledge the following funding sources, Antiviral Drug Discovery and Development Center (5U19Al109680 and (1U19Al142759) awarded to M.D. and R.S.B, a partnership grant from the National Institutes of Allergy and Infectious Disease (NIAID, 5R01Al132178) awarded to T.P.S. and R.S.B. and an NIAID R01 grant (Al108197) awarded to M.D. and R.S.B.. NIAID contract, HHSN272201500008C, was awarded to G.P. and The Emory institute for Drug Development and a subcontract from this was awarded to R.S.B. and M.R.D. M.L.A. was funded through training grants F31Al133952 and T32Al112541. The Marsico lung Institute Tissue Procurement and Cell Culture Core is supported by NIH grant DK065988 and Cystic Fibrosis Foundation grant BOUCHE15RO. Author contributions: A.C.S., T.P.S, A.J.P. and M.L.A. designed in vitro efficacy studies. A.C.S., A.J.B., T.P.S., R.L.G. A.J.P., L.J.S., and M.L.A. executed and/or analyzed in vitro efficacy studies. X.L., T.M.H. and A.S.G. designed, optimized and/or executed the SARS-CoV-2 qRT-PCR studies. J.H., A.T. and N.J.T. providing the clinical isolate of SARS-CoV-2. T.P.S., A.A.K., M.G.N., G.P. and R.S.B. designed in vivo efficacy studies. T.P.S., A.C.S., S.Z., C.S.H, and R.S. designed, executed and/or analyzed the Primer ID NGS data. K.H.D $3^{\text {rd }}$ performed structural modeling and phylogenetics and sequence alignments. M.L.A., A.J.P., J.D.C. and M.R.D. designed, performed and/or executed the construction of RDV resistant MHV and performed crossresistance studies. T.P.S., A.S. and S.R.L. executed and analyzed in vivo efficacy studies. A.S. and S.R.L. performed whole body plethysmography for in vivo studies. S.A.M. assessed all lung pathology. G.R.B., and M.S., were responsible for synthesis, and scale-up of small molecules. T.P.S., A.C.S., S.Z., S.R.L, A.S., K.H.D. ${ }^{\text {rd }}$, M.L.A., A.J.P., J.D.C, G.R.B., A.A.K., G.P., R.S., M.R.D., and R.S.B., wrote the manuscript. Disclaimers: The findings and conclusions in this report are those of the author(s) and do not necessarily represent the official position of the Centers for Disease Control and Prevention. Names of specific vendors, manufacturers, or products are included for public health and informational purposes; inclusion does not imply endorsement of the vendors, manufacturers, or products by the Centers for Disease Control and Prevention or the US Department of Health and Human Services. Competing financial interests: UNC is pursuing IP protection for Primer ID and R.S. has received nominal royalties. G.R.R, M.G.N., and G.R.P hold patents 62096915, 62201140, 2015066144, 62306163, 2017021759, 16083177, 62595907, 62626998, 62760434, 2018064503, 62971559, and 62988133, "N4-Hydroxycytidine and Derivatives and Anti-Viral Uses Related Thereto," relating to this work. This study could affect their personal financial status. Data and Materials Availability: All data associated with this study are present in the paper or Supplementary Materials. Sequence data are deposited to NCBI SRA as PRJNA613261 and PRJNA613454 This work is licensed under a Creative Commons Attribution 4.0 International (CC BY 4.0) license, which permits unrestricted use, distribution, and reproduction in any medium, provided the original work is properly cited. To view a copy of this license, visit http://creativecommons.org/licenses/by/4.0/. This license does not apply to figures/photos/artwork or other content included in the article that is credited to a third party; obtain authorization from the rights holder before using such material.

Submitted 5 March 2020

Accepted 2 April 2020

Published First Release 6 April 2020

10.1126/scitransImed.abb5883 

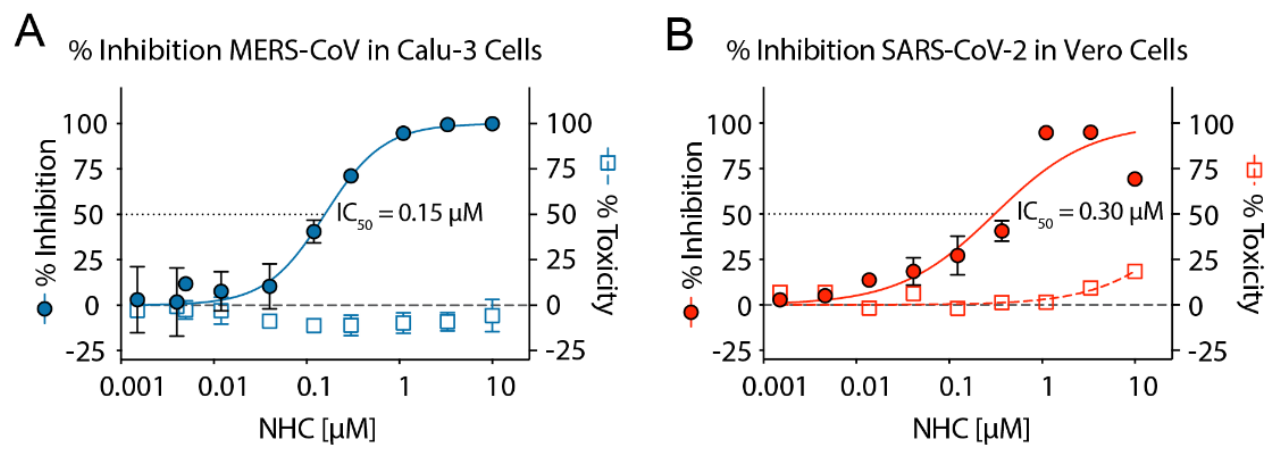

C SARS-CoV-2 Titer Reduction in Calu-3 Cells

$$
\% \text { Inhibition SARS-CoV-2 in Calu-3 Cells }
$$
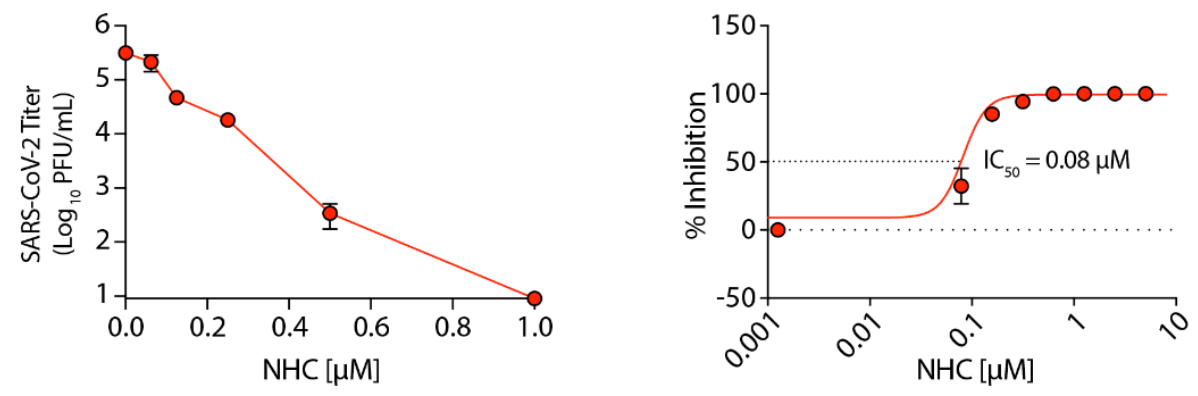

SARS-CoV-2 Genome Reduction in Calu-3 Cells

$$
\% \text { Inhibition SARS-CoV-2 in Calu-3 Cells }
$$
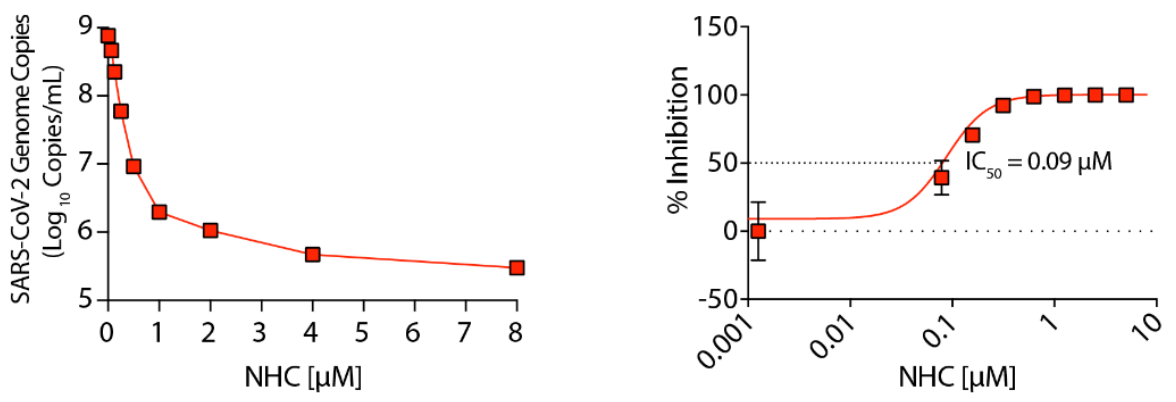

Fig. 1. NHC potently inhibits MERS-CoV and newly emerging SARS-CoV-2 replication. (A) Percent inhibition of MERS-CoV replication and NHC cytotoxicity in Calu-3 cells. Calu-3 cells were infected in triplicate with MERS-CoV nanoluciferase (nLUC) at a multiplicity of infection (MOI) of 0.08 in the presence of a range of drug for 48 hours, after which replication was measured through quantitation of MERS-CoV-expressed nLUC. Cytotoxicity was measured in similarly treated but uninfected cultures via Cell-Titer-Glo assay. Data are combined from 3 independent experiments. (B) NHC antiviral activity and cytotoxicity in Vero E6 cells infected with SARS-CoV-2. Vero E6 cells were infected in duplicate with SARS-CoV-2 clinical isolate $2019-n C o V / U S A-W A 1 / 2020$ virus at an MOI of 0.05 in the presence of a range of drug for 48 hours, after which replication was measured through quantitation of cell viability by Cell-Titer-Glo assay. Cytotoxicity was measured as in A. Data are combined from 2 independent experiments. (C) SARS-CoV-2 titer reduction (left) and percent inhibition (right) in Calu- 3 cells. Cells were infected with at an $\mathrm{MOI}$ of 0.1 for $30 \mathrm{~min}$, washed and exposed to a dose response of NHC in triplicate per condition. 72 hours post infection, virus production was measured by plaque assay. (D) SARS-CoV-2 genomic RNA reduction (left) and percent inhibition (right) in Calu-3 cells. Viral RNA was isolated from clarified supernatants from the study in panel C. Genome copy numbers were quantitated by qRT-PCR with primer/probes targeting the $\mathrm{N}$ gene. For $\mathrm{A}-\mathrm{D}$, the symbol is at the mean and the error bars represent the standard deviation. 
A

SARS-CoV-2:

Virus production in $\mathrm{HAE}$

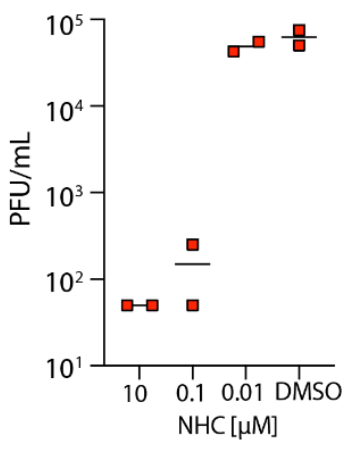

B

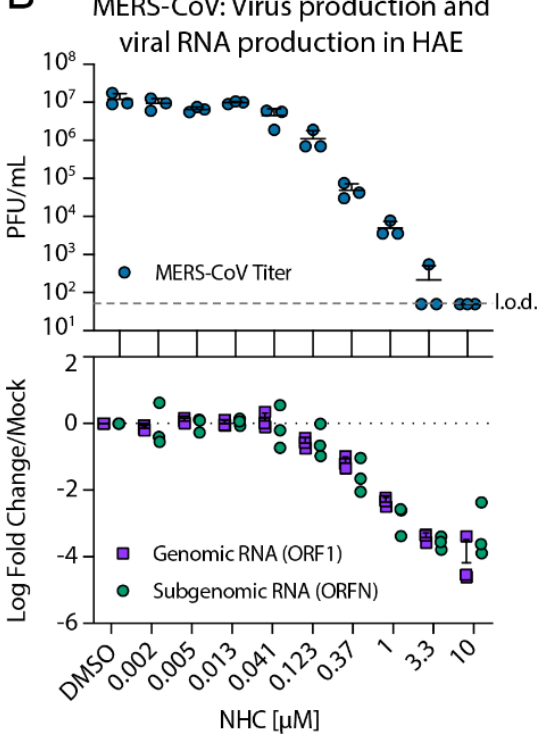

C SARS-COV: Virus production and $10^{8}$ viral RNA production in HAE

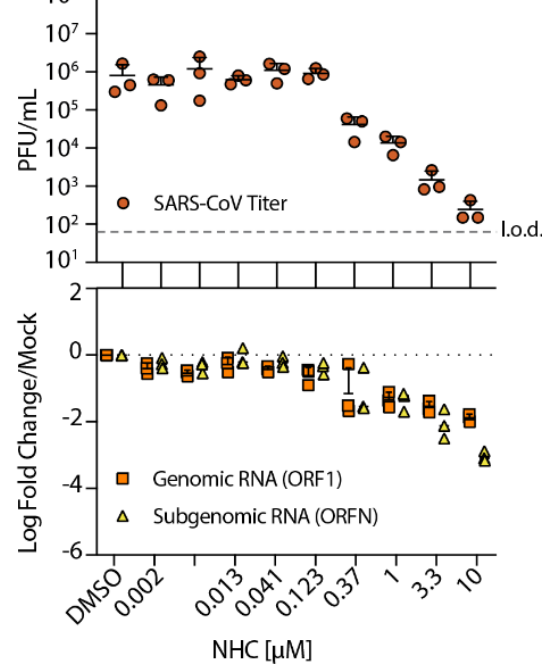

Fig. 2. NHC is highly active against SARS-CoV-2, MERS-CoV, and SARS-CoV in primary human airway epithelial cell cultures. (A) HAE were infected at an $\mathrm{MOI}$ of 0.5 with clinical isolate SARS-CoV2 for 2 hours in the presence of NHC in duplicate after which virus was removed and cultures were washed in incubated in NHC for 48 hours when apical washes were collected for virus titration by plaque assay. The line is at the mean. Each symbol represents the titer from a single well. (B) HAE cells were infected with MERS-CoV red fluorescent protein (RFP) at an MOI of 0.5 in triplicate and treated similarly to A. qRT-PCR for MERS-CoV ORF1 and ORFN mRNA. Total RNA was isolated from cultures in C for qRT-PCR analysis. Representative data from three separate experiments with three different cell donors are displayed. PFU, plaque-forming units. (C) Studies performed as in A but with SARSCoV green fluorescent protein (GFP). Representative data from two separate experiments with two different cell donors are displayed. Each symbol represents the data from one HAE culture, the line is at the mean and the error bars represent the standard deviation. 

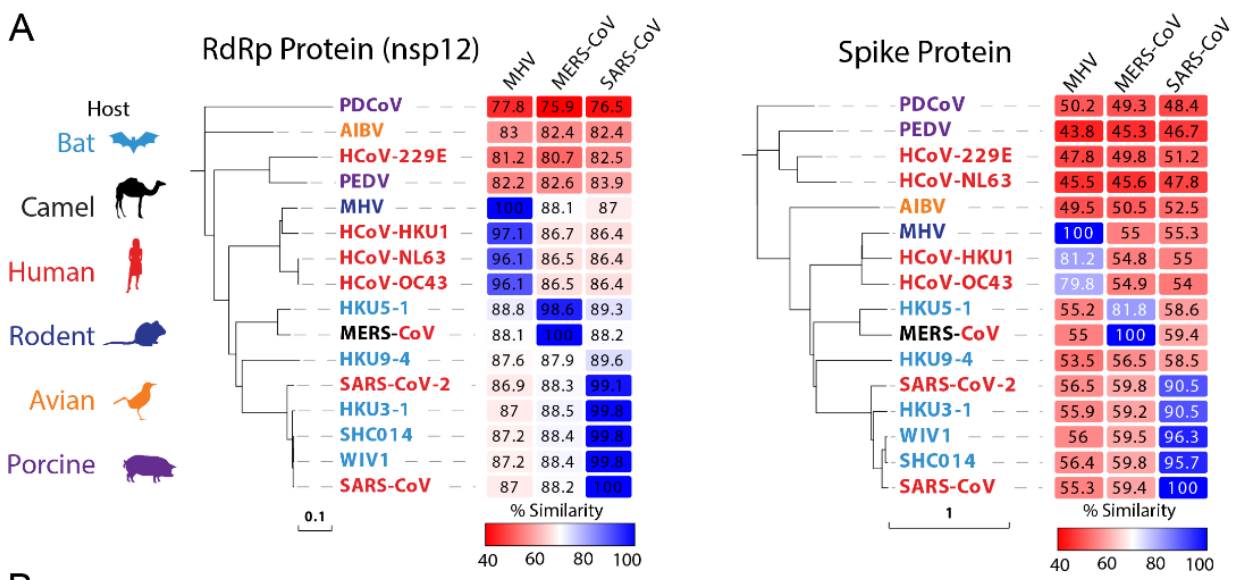

B

Family-wide conservation of RNA interaction sites
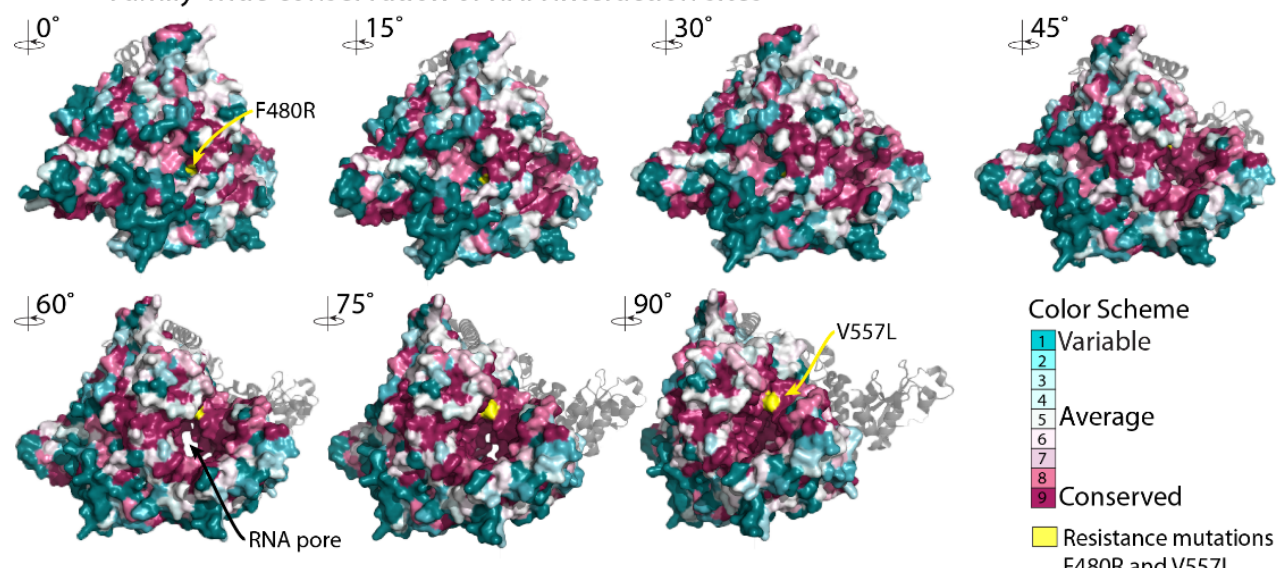

C

\begin{tabular}{cc}
\multicolumn{3}{c}{ Conserved resistance motifs } \\
F476L & V553L \\
PDCoV DKYLEPY & ARTVAGV \\
$229 E$ ARYFDCY & ARTVGGV \\
NL63 YKYFEIY & ARTVAGV \\
OC43 YKYFEIY & ARTVAGV \\
MHV NKYFEIY & ARTVAGV \\
HKU1 YKYFEIY & ARTVAGV \\
MERS NKYFEIY & ARTVAGV \\
HKU9-4 DKYFDCY & ARTVAGV \\
SARS-CoV-2 DKYFDCY & ARTVAGV \\
HKU3 DKYFDCY & ARTVAGV \\
SARS-CoV DKYFDCY & ARTVAGV \\
SHC014 DKYFDCY & ARTVAGV \\
\multicolumn{3}{c}{ F } \\
F40L SARS-CoV & V557L in SARS-CoV
\end{tabular}

D Cross-susceptibility of RDV-resistant virus

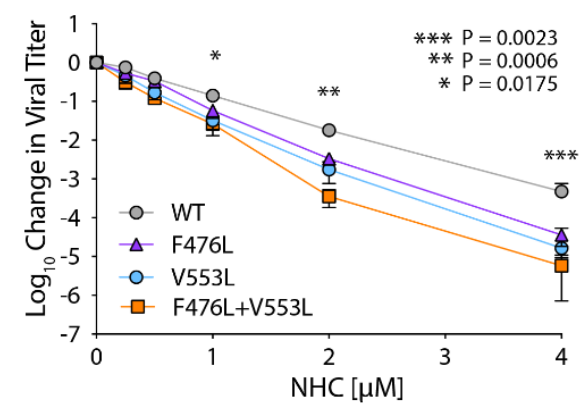

Fig. 3. Remdesivir (RDV) resistance mutations in the highly conserved RNA-dependent RNA polymerase increase susceptibility to NHC. (A) Neighbor-joining trees created with representatives from all four CoV genogroups showing the genetic similarity of CoV nsp12 (RdRp) and CoV spike glycoprotein, which mediates host tropism and entry into cells. Text color of the virus strain label corresponds to virus host species on the left. The heatmap adjacent to each neighbor-joining tree depicts percent amino acid identity (\% A.A. similarity) against mouse hepatitis virus (MHV), SARS-CoV, or MERS-CoV. (B) The variation encompassed in panel A was modeled onto the RdRp structure of the SARS-CoV RdRp. (C) Amino acid sequence of CoV in panel A at known resistance alleles to antiviral drug RDV. (D) Virus titer reduction assay in DBT cells across a range of NHC with recombinant MHV bearing resistance mutations to RDV. Data shown are combined from three independent experiments performed with biological duplicates or triplicates per condition. Asterisks indicate statistically significant differences by Mann-Whitney test as indicated on the graph. 
Infectious virus production and viral RNA production in HAE

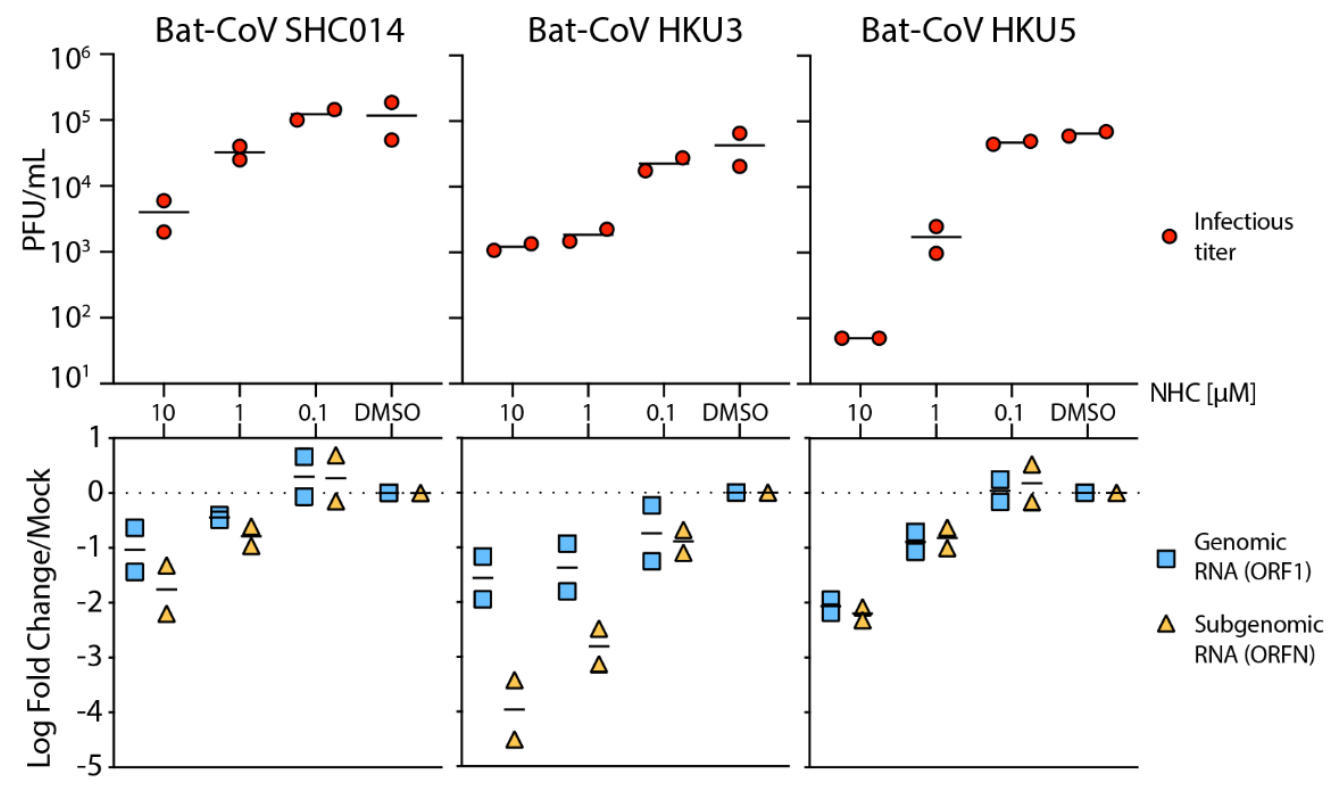

Fig. 4. NHC is effective against multiple genetically distinct Bat-CoV. Top: Antiviral efficacy of NHC in HAE cells against SARS-like (HKU3, SHC014, group 2b) and MERS-like (HKU5, group 2c) bat-CoV. $\mathrm{HAE}$ cells were infected at an $\mathrm{MOI}$ of 0.5 in the presence of $\mathrm{NHC}$ in duplicate. After 48 hours, virus produced was titrated via plaque assay. Each data point represents the titer per culture. Bottom: qRTPCR for CoV ORF1 and ORFN mRNA in total RNA from cultures in the top panel. Mock, mock-treated. Representative data from two separate experiments with two different cell donors are displayed. 
A

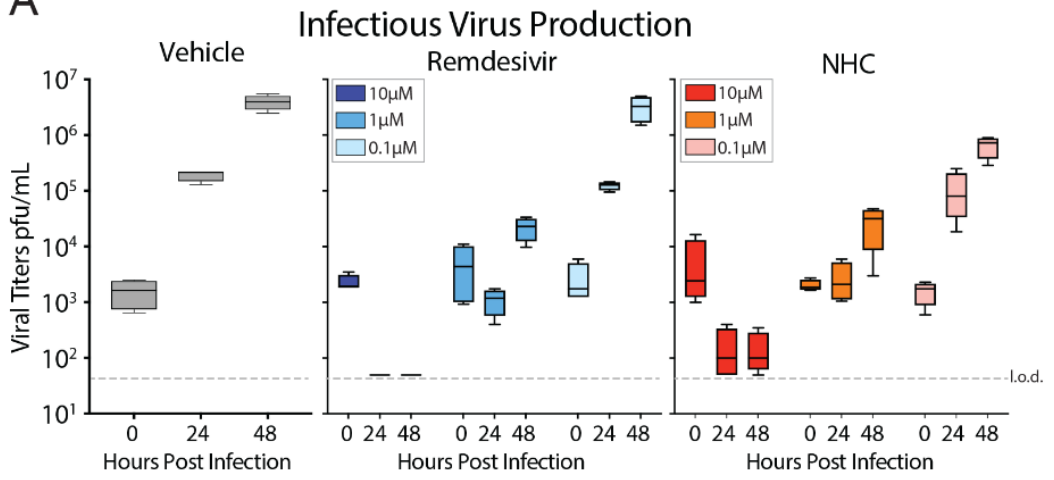

C

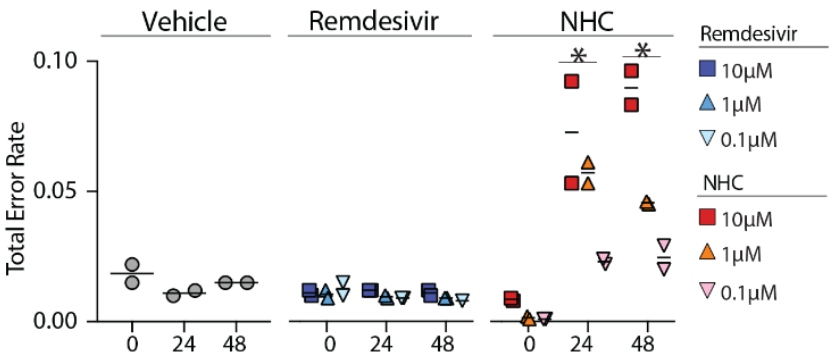

D NHC Mutational Spectrum

\begin{tabular}{|c|c|c|c|c|}
\hline $\begin{array}{c}\text { Input } \\
\begin{array}{c}\text { Genomic } \\
\text { +RNA }\end{array}\end{array}$ & $\begin{array}{c}\text { Genomic } \\
\text {-RNA }\end{array}$ & $\begin{array}{c}\text { Progeny } \\
\text { Genomic } \\
\text { +RNA }\end{array}$ & $\begin{array}{c}\text { DNA } \\
\text { Amplicon }\end{array}$ & $\begin{array}{c}\text { Genomic } \\
\text { Mutation }\end{array}$ \\
\hline A & E & A & A & \\
\hline A & E & G & G & A to G \\
\hline G & E & G & G & \\
\hline G & E & A & A & G to A \\
\hline C & G & E & C & \\
\hline C & G & E & T & C to U \\
\hline U & A & E & T & \\
\hline U & A & E & C & U to C \\
\hline
\end{tabular}

Example of $\mathrm{NHC}$ incorporated as " $\mathrm{C}$ " or " $\mathrm{U}$ " Input Genomic +RNA 5'-GCUACAAGUUCGUCCUUUGG-3' Genomic-RNA 3'-EGTEGEUEAAGCAGGAAACC-5' Progeny +RNA 5'-GCUACGAAUUEGUECEEUGG-3' DNA Amplicon 5'-GCTACGAATTCGTTCTCTGG-3' $E=N H C(E I D D-1931)$
$B$ Primer ID to sequence single genomes

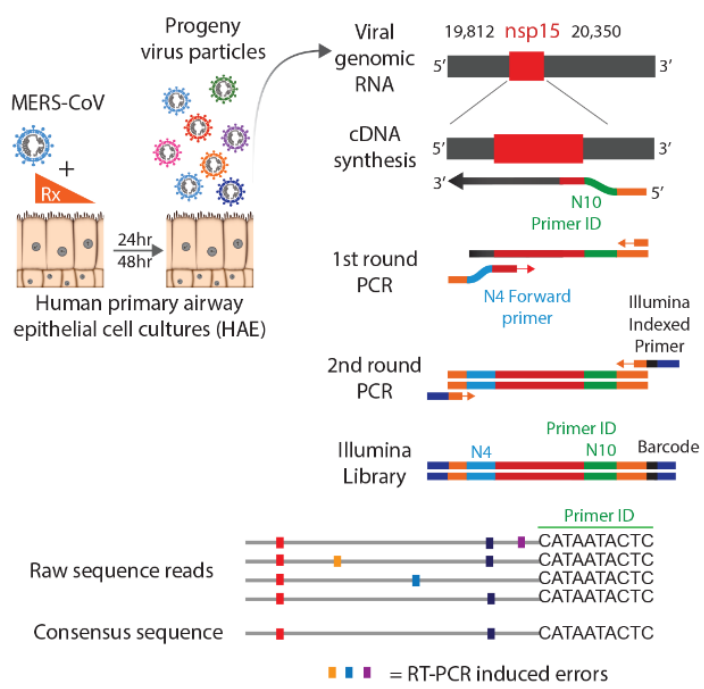

E Substitution Rate: NHC vs. Remdesivir

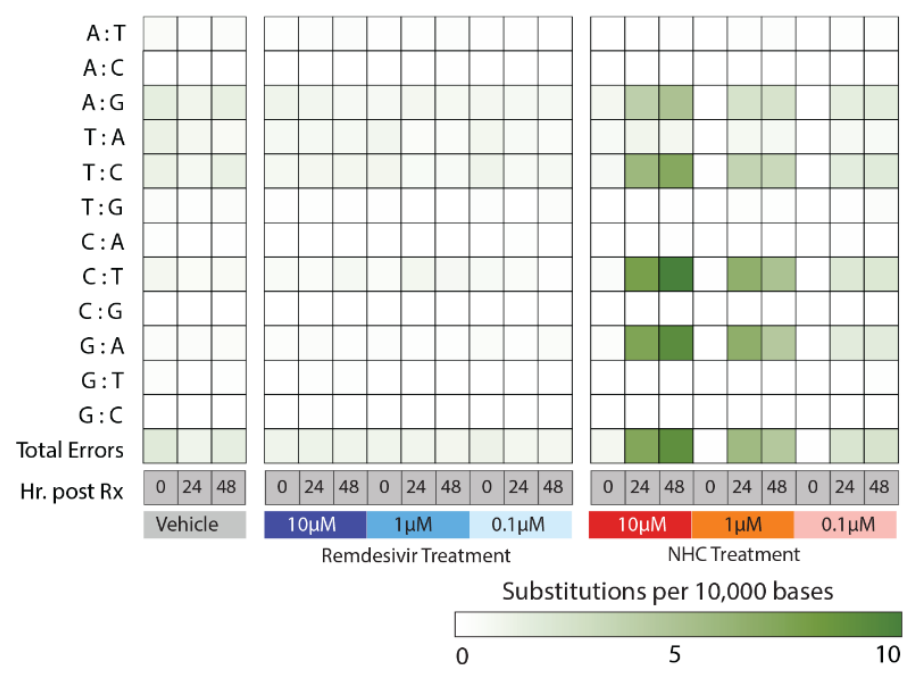

Fig. 5. NHC antiviral activity is associated with increased viral mutation rates. (A) HAE cultures were infected with MERS-CoV red fluorescent protein (RFP) at an MOI of 0.5 in duplicate in the presence of vehicle, RDV, or $\mathrm{NHC}$ for 48 hours, after which apical washes were collected for virus titration. Data are combined from two independent studies. The boxes encompass the 25th to 75th percentile, the line is at the median, while the whiskers represent the range. (B) Schematic of Primer ID deep sequencing for single RNA genomes of MERSCoV. (C) The total error rate for MERS-CoV RNA isolated from cultures in panel A as determined by Primer ID. Error rate values are \# mutations per 10,000 bases. Asterisks indicate significant differences as compared to untreated group by two-way ANOVA with a Dunnett's multiple comparison test. (D) Description of potential NHC mutational spectra on both positive and negative sense viral RNA. (E) Nucleotide transitions in cDNA derived from MERS-CoV genomic RNA. 

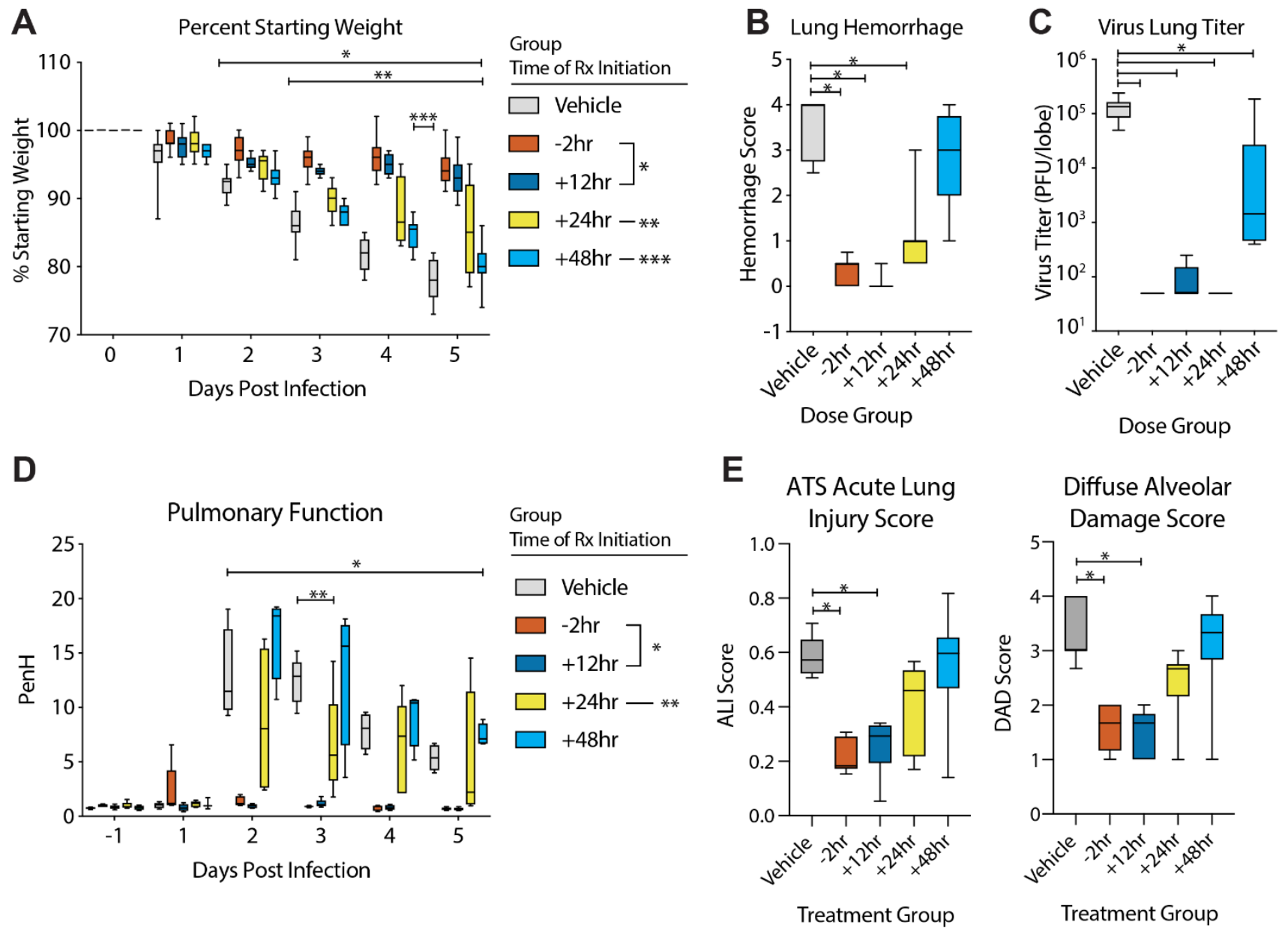

Fig. 6. Prophylactic and therapeutic EIDD-2801 reduces SARS-CoV replication and pathogenesis. Equivalent numbers of 25-29 week old male and female C57BL/6 mice were administered vehicle (10\% PEG, $2.5 \%$ Cremophor RH40 in water) or NHC prodrug EIDD-2801 beginning at -2 hours, $+12,+24$ or +48 hours post infection and every 12 hours thereafter by oral gavage $(n=10 /$ group). Mice were intranasally infected with 1E+04 PFU mouse-adapted SARS-CoV MA15 strain. (A) Percent starting weight. Asterisks indicate differences from vehicle treated by two-way ANOVA with Tukey's multiple comparison test. (B) Lung hemorrhage in mice from panel $A$ scored on a scale of $0-4$ where 0 is a normal pink healthy lung and 4 is a diffusely discolored dark red lung. (C) Virus lung titer in mice from panel A as determined by plaque assay. Asterisks in both panel $B$ and $C$ indicate differences from vehicle by one-way ANOVA with a Dunnett's multiple comparison test. (D) Pulmonary function by whole body plethysmography was performed daily on five animals per group. Asterisks indicate differences from vehicle by two-way ANOVA with a Dunnett's multiple comparison test. (E) The histological features of acute lung injury (ALI) were blindly scored using the American Thoracic Society Lung Injury Scoring system and a Diffuse Alveolar Damage Scoring System. Three randomly chosen high power (60X) fields of diseased lung were assessed per mouse. The numbers of mice scored per group: Vehicle $N=7,-2$ hours $N=9,+12$ hours $N=9,+24$ hours $N=10,+48$ hours $N=9$. Asterisks indicate statistical significance compared to vehicle by Kruskal-Wallis with a Dunn's multiple comparison test. For all panels, the boxes encompass the 25th to 75th percentile, the line is at the median, while the whiskers represent the range. ${ }^{*},-2$ hours and +12 hours compared to vehicle; **, +24 hours compared to vehicle; ${ }^{* *},+48$ hours compared to vehicle. 

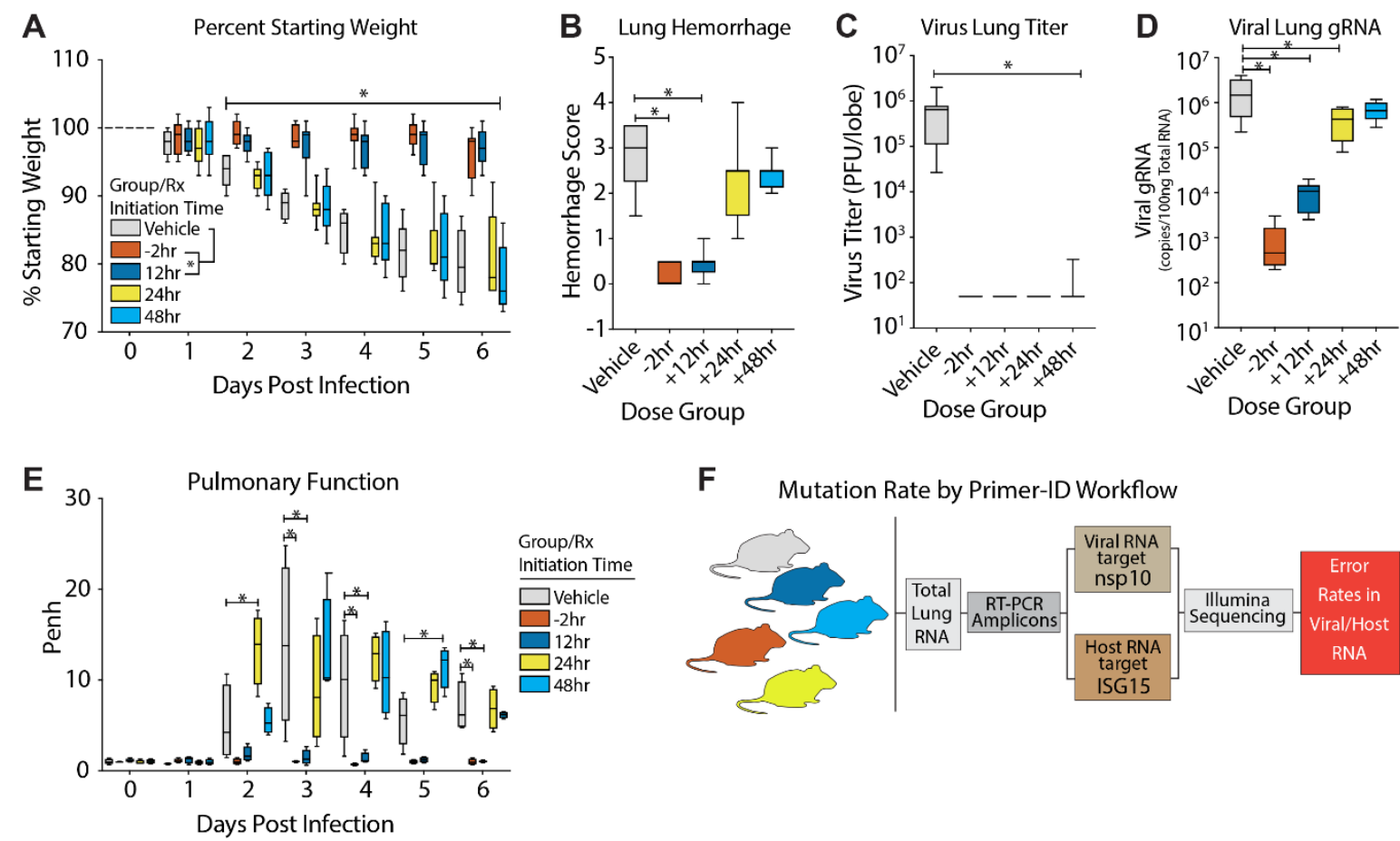

F Mutation Rate by Primer-ID Workflow

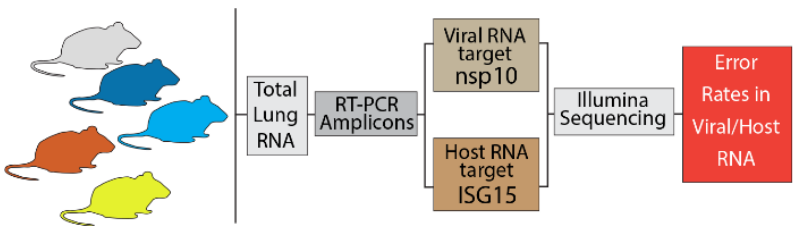

G Number of Template Consensus Sequences

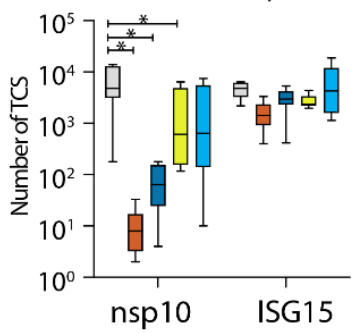

H

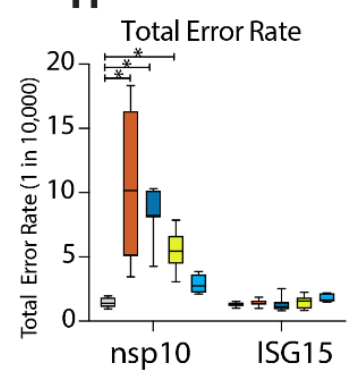

I

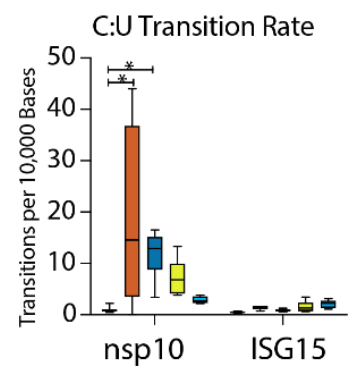

J nsp10 Codon Change Frequency

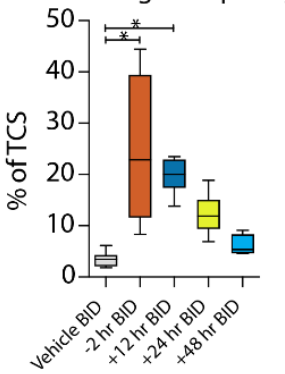

Group/Rx Initiation Time Inehicle $-2 \mathrm{hr}$ $-2 \mathrm{hr}$
$12 \mathrm{hr}$ $12 \mathrm{hr}$ $24 \mathrm{hr}$

Fig. 7. Prophylactic and therapeutic EIDD-2801 reduces MERS-CoV replication and pathogenesis coincident with increased viral mutation rates. Equivalent numbers of 10-14 week old male and female C57BL/6 hDPP4 mice were administered vehicle (10\% PEG, 2.5\% Cremophor RH40 in water) or NHC prodrug EIDD-2801 beginning at -2 hours, $+12,+24$ or +48 hours post infection and every 12 hours thereafter by oral gavage $(n=10 /$ group $)$. Mice were intranasally infected with 5E+04 PFU mouse-adapted MERS-CoV M35C4 strain. (A) Percent starting weight. Asterisks indicate differences between -2 hours and +12 hours group from vehicle by two-way ANOVA with Tukey's multiple comparison test. (B) Lung hemorrhage in mice from panel A scored on a scale of 0-4 where 0 is a normal pink healthy lung and 4 is a diffusely discolored dark red lung. (C) Virus lung titer in mice from panel A as determined by plaque assay. Asterisks in both panel $B$ and $C$ indicate differences from vehicle by Kruskal-Wallis with Dunn's multiple comparison test. (D) MERS-CoV genomic RNA in lung tissue by qRT-PCR. Asterisks indicate differences by one-way ANOVA with a Dunnett's multiple comparison test. (E) Pulmonary function by whole body plethysmography was performed daily on four animals per group. Asterisks indicate differences from vehicle by two-way ANOVA with Tukey's multiple comparison test. (F) Workflow to measure mutation rate in MERS-CoV RNA and host transcript ISG15 by Primer ID in mouse lung tissue. (G) Number of template consensus sequences (TCS) for MERS-CoV nsp10 and ISG15. (H) Total error rate in MERS-CoV nsp10 and ISG15. (I) The cytosine to uridine transition rate in MERSCoV nsp10 and ISG15. In panels G-I, asterisks indicate differences from vehicle by two-way ANOVA with Tukey's multiple comparison test. $(J)$ Codon change frequency in MERS-CoV nsp10. Asterisks indicate differences from vehicle by Kruskal-Wallis with Dunn's multiple comparison test. For all panels, the boxes encompass the 25th to 75th percentile, the line is at the median, while the whiskers represent the range. 